

\section{DISCLAIMER}

This report was prepared as an account of work sponsored by an agency of the United States Government. Neither the United States Government nor any agency Thereof, nor any of their employees, makes any warranty, express or implied, or assumes any legal liability or responsibility for the accuracy, completeness, or usefulness of any information, apparatus, product, or process disclosed, or represents that its use would not infringe privately owned rights. Reference herein to any specific commercial product, process, or service by trade name, trademark, manufacturer, or otherwise does not necessarily constitute or imply its endorsement, recommendation, or favoring by the United States Government or any agency thereof. The views and opinions of authors expressed herein do not necessarily state or reflect those of the United States Government or any agency thereof. 


\section{DISCLAIMER}

Portions of this document may be illegible in electronic image products. Images are produced from the best available original document. 


\title{
Chromatographic Measurement of Hydrogen Isotopic and Permanent Gas Impurities in Tritium
}

\author{
David K. Warner, Christopher Kinard and Donald R. Bohl
}

June 4, 1976

\section{NOTICE}

This report was prepared as an account of work sponsored by the United States Government. Neither the United States nor the United States Energy Research and Development Administration, nor any of their employees, nor any of their contractors, subcontractors, or their employees, makes any warranty, express or implied, or assumes any legal liability or responsibility for the accuracy, com-

pleteness or usefulness of any information, apparatus, product or process disclosed or represents that its use would not infringe privately owned rights.

PRINTED IN THE UNITED STATES OF AMERICA.

Available from

National Technical Information Service

U. S. Department of Commerce

5285 Port Royal Road

Springfield, Virginia 22161

Price: Printed Copy \$4.00; Microfiche $\$ 2.25$

\section{MONSANTO RESEARCH CORPORATION}

A Subsidiary of Monsanto Company

\section{mOUnD IABORATORY}

Miamisburg, Ohio

45342

operated for

\section{UNITED STATES ENERGY RESEARCH AND DEVELOPMENT ADMIINISTRATION}

U. S. Government Contract No. E-33-1-GEN-53 
Table of Contents

Page

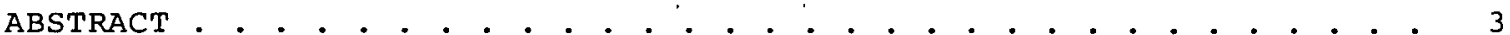

INTRODUCTION

A. Overview of Project . . . . . . . . . . . . . . . . . . 3

B. Scope of Work............................ . . . . . . . 3

C. Instrument Capabilities . . . . . . . . . . . . . . . . . . 4

THE INSTRUMENT SYSTEM

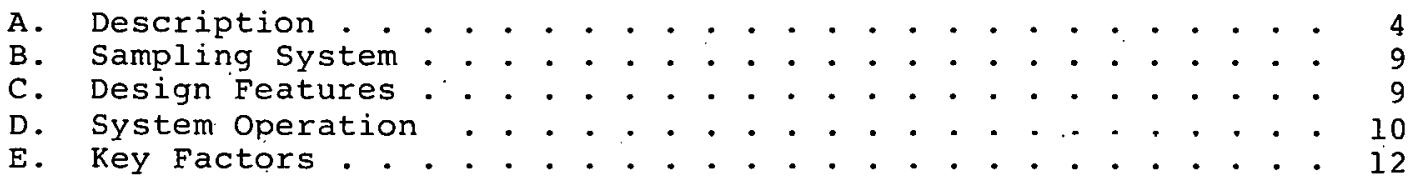

SYSTEM CALIBRATION

A. Pressure Transducer . . . . . . . . . . . . . . . . 13

B. Calibration Gases . . . . . . . . . . . . . . . . . . . . 13

C. System Calibration Procedure . . . . . . . . . . . . . . . 14

D. Method of Computing Results . . . . . . . . . . . . . . . . 14

SYSTEM RELIABILITY: METHOD PERFORMANCE

A. Precision . . . . . . . . . . . . ........ . 15

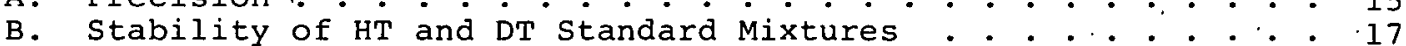

C. Integration of Overlapping Peaks . . . . . . . . . . . . . . 17

D. Method Accuracy . . . . . . . . . . . . . . . . . . . 20

E. High Probability Systematic Errors . . . . . . . . . . . . . 2 I

F. Error Curves at Low Concentrations . . . . . . . . . . . . . 22

LIMITATIONS OF PRESENT SYSTEM

A. Manual Operation - Sample Throughput . . . . . . . . . . 23

B. Ortho-Para Isomer Separation ... . . . . . . . . . . . . . 23

C. Limited Analytical Range . . . . . . . . . . . . . . . . . . . . 23

REFERENCES . . . . . . . . . . . . . . . . . . . . . . . . . . . 24

BIBLIOGRAPHY . . . . . . . . . . . . . . . . . . . . . . . . 24

ACKNOWLEDGEMENTS . . . . . . . . . . . . . . . . . . . . . . . . . . 24

APPENDICES

APPENDIX A: Complete Flow Schematic and Parts List . . . . . . 25

APPENDIX B: Error Curve for Impurity Determinations . . . . . 28 


\begin{abstract}
This paper describes a gas chromatograph that was designed for dedicated analysis of hydrogen isotopic and permanent gas impurities in tritium and tritiumdeuterium mixtures. The instrument that was developed substantially improved the accuracy and precision of hydrogen isotopic analysis in the $20 \mathrm{ppm}$ to one mole percent range as compared with other analytical methods used at Mound Laboratory. Several unique design
\end{abstract}

Abstract

features of the instrument. were required due to the radiation and isotopic exchange properties of the tricium in the samples; descriptions of these features are presented along with details of the complete chromatographic system. The experimental procedures used to calibrate the detector and statistically evaluate its performance are given, and the sources of analytical error are cited. The limitations of the present system are also discussed.

\title{
Introduction
}

\section{A. OVERVIEW OF PROJECT}

The use of gas chromatography (GC) for qualitatively separating the hydrogen isotopes has been previously demonstrated by several investigators, ${ }^{-3}$ and a brief description of its use as a quantitative method has also been published. ${ }^{4}$ Chromatography has also proven itself to be invaluable for a variety of permanent gas analyses over the past two decades. 5.6 Even with its demonstrated potential for sensitive, accurate, and low cost applications in gas analysis, the GC techniques have not been fully developed and exploited as a viable analytical method for the determination of hydrogen isotopes and impurities contained in isotopic mixtures.

This report describes the development of a cryogenic gas chromatograph with a design expressly intended for the determination of hydrogen isotopic and certain permanent gas impurities in isotopic mixtures and purified isotopes. The successful conclusion of this task in June, 1973, has enhanced the analytical capability at Mound Laboratory for the analysis of isotopic hydrogen mixtures from the laboratory's recovery operations. The sensitivity of the gas chromatograph and the scope of its various applications have greatly rewarded the effort placed in its development.

\section{B. SCOPE OF THE WORK}

The capability most desired in the gas chromatograph was deemed to be that of determining low concentration levels of the hydrogen isotopic impurities HD, HT,
DT, and the tritium decay product helium-3. Also desired was the capability of determining low levels of the permanent gases argon and nitrogen in gases containing tritium.

The scope of the instrument development activities was limited to achieving the design and construction of a dedicated gas chromatograph for determining the isotopic and permanent gas impurities at levels of $1 \%$ or less. The work scope included the definition of the accuracy and precision of the analytical methods. Listed below are each gas impurity included in the development effort and the reasons for its inclusion. exchange with deuterium or tritium. Sources of hydrogen are primarily vessel surfaces.

b. DT

: Deuterium (as DT) is a principal impurity in tritium.

c. Helium-3 : Always present as a decay product in tritium-containing gases.

d. Argon, : Both present in boxline Nitrogen atmosphere and could potentially be introduced into process lines by leakage or accidents.

Although the gas chromatographic technique is applicable to other impurities which spuriously occur in the tritium recovery operations, the present investigation was limited to the above list. 


\section{INSTRUMENT CAPABILITIES}

The specific determinations for which the gas chromatograph was designed are listed in Table 1 . The lower limits of detection for impurity components were established to be $20 \mathrm{ppm}$ for the argon and nitrogen species for a sample volume of $1 \mathrm{~cm}^{3}$ and $300 \mathrm{~mm} \mathrm{Hg}$ pressure, and $50 \mathrm{ppm}$ for, the isotopic species helium-3, HD, HT, and DT at the same volume and pressure. The majority of experimental results has been less than $2000 \mathrm{ppm}$, but determinations as high as $4 \%$ (volume percent) have been performed accurately. Although the intent of the chromatograph was to perform analyses of the low level impurities, the methods are applicable to concentrations up to roughly 58 without special calibration at the higher end of the range. Complete precision and accuracy statements are included in section IV.

Table 1

TYPE OF ANALYSES

PERFORMED BY CHROMATOGRAPHY

Components
Determined

Ar, $\mathrm{N}_{2}$

${ }^{3} \mathrm{He}, \mathrm{HT}, \mathrm{DT}$

Purified $\mathrm{T}_{2}$ $\mathrm{H}_{2}, \mathrm{D}_{2},{ }^{3} \mathrm{He}$ Mixtures

HD

Purified $\mathrm{T}_{2}$

HD, HT
$\mathrm{D}_{2}$

Isotopic Mixtures of ${ }^{3} \mathrm{He}, \mathrm{D}_{2}, \mathrm{~T}_{2}$

\section{The Instrument System}

\section{A. DESCRIPTION}

Since many of the construction details are unique to the analysis of radioactive gases and are substantially different from commercial instruments, the gas chromatographic system will be described in detail. Several of the criteria used in designing the instrument were the following:
a. A leak-free system for containment of tritium.
b. Facilities for proper disposal of tritium-containing, gases.
c. Ease of maintenance inside a glove- box.
d. Versatility in sampling capability.
e. Relatively small size for placement in glovebox.

The instrument may be described as "dedicated" in the sense that it performs only impurity analyses in hydrogen isotopic gases and does not possess the experimental versatility of general purpose commercial instruments. For example, no full range temperature controls are provided for either the detector or the columns, the carrier gas flow control is not continuously variable, and columns are not routinely exchangeable. Experimental versatility was eliminated from the inception of the design in order to simplify the operation of the instrument within a glovebox.
The design may be visualized by referring to Figure 1, a slightly simplified gas flow diagram of the chromatograph, * and Figure 2, a photograph of the instrument portion contained in the glovebox.

In Figure 1, the gas sampling valves are represented by circles. The valving to the left of the two gas sampling valves is the manifold for transferring sample gas from sources to the appropriate sampling valve and also for removing by vacuum or $\mathrm{U}-\mathrm{Bed}$ any gas remaining in the sampling valves or manifold after the sampling operations. The flow pattern to the right of the gas sampling valves in Figure 1 represents the functions of (1) separation of gas components, (2). detection of these components, and (3) continuous removal of the carrier gas from the instrument.

The carrier gas (helium-4 or noon) is fed to the instrument from a cylinder located outside the glovebox, and valves (not illustrated in Figure 1) are provided to isolate the instrument from the carrier gas supply when the instrument is not in operation. As the carrier gas is introduced into the instrument, the flow is split and half the carrier gas is routed

\footnotetext{
* Some valving has been simplified or eliminated from Figure 1 to emphasize the basic flow pattern and component arrangement. A complete flow schematic may be found in Appendix $A$.
} 


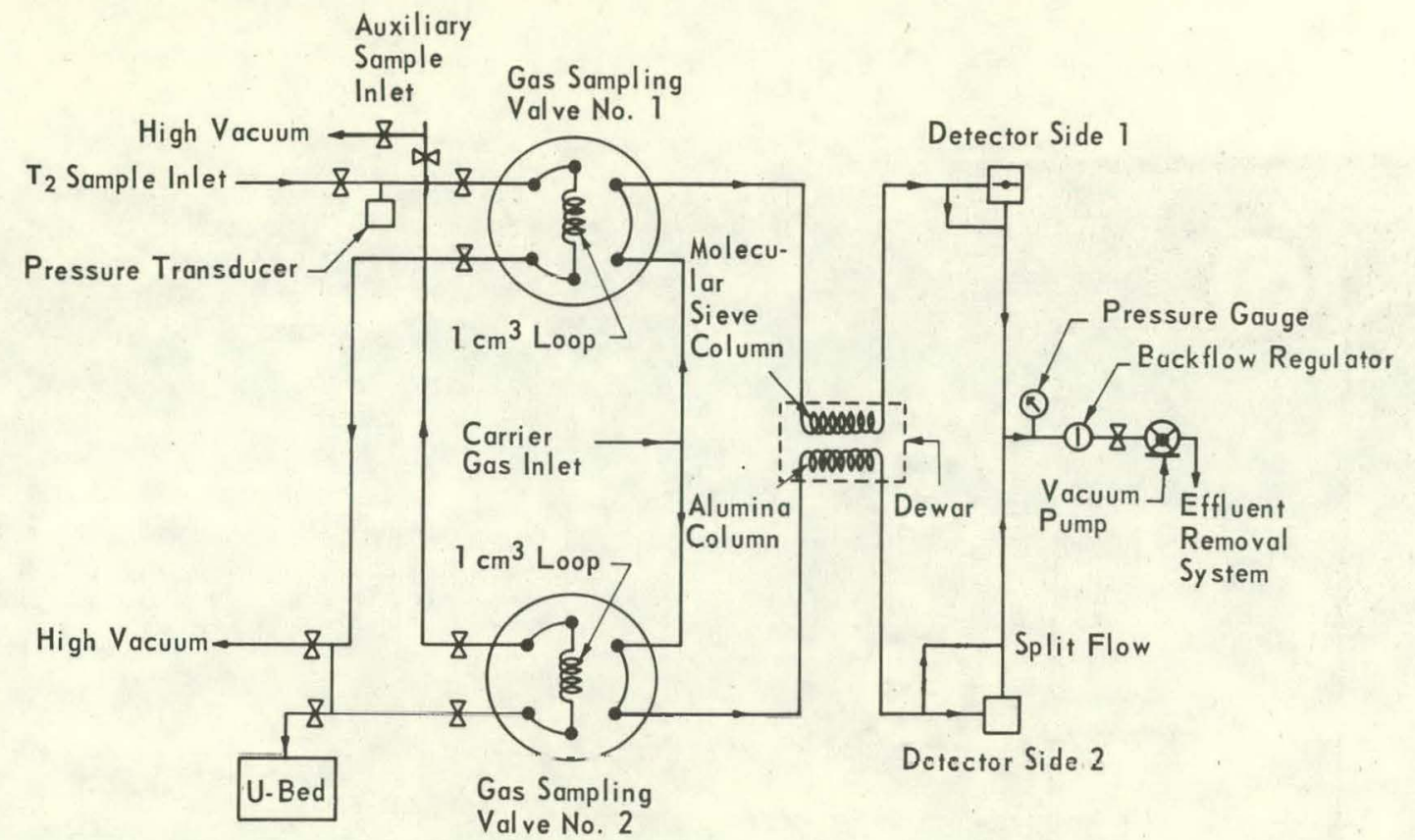

FIGURE 1 - Gas chromatography flow diagram.

to each gas sampling valve. Each sampling valve services only one column, and each valve samples gas independently of the other sampling valve. The sample loop volumes are nominally $1 \mathrm{~cm}^{3}$, and carrier gas flow is not interrupted significantly by the introduction of the sample into the carrier gas stream. The carrier gas flow continues to the two analytical columns; the molecular sieve column is used for the separation of argon and nitrogen from the hydrogen isotopes, and the alumina column is uscd for the isotopic separation. Carrier gas flows continuously through both columns during the operation of the instrument regardless of which analytical separation is being per furmed.

The two columns are coiled together and are located in a controlled ventilation area below the glovebox. A photograph of the columns and a dewar for envelopment of the columns in liquid nitrogen is shown in Figure 3 . The columns are placed in liquid nitrogen for the isotopic separations, but ambient column temperature is used for the argon, nitrogen separation. These columns were placed outside the controlled-atmosphere glovebox for three reasons:

a. To preclude difficulties with glovebox pressure regulation during introduction of liquid nitrogen into the boxline. b. To simplify the transfer and handling of the liquid nitrogen.

c. To isolate the detector from severe local temperature variations caused by the use of liquid nitrogen inside the glovebox.

The carrier gas, after passing through the columns (see Figure 1), continues to the detector, which is a microthermistor thermal conductivity detector. Each gas stream is again split at the detector with roughly $1 / 4$ of the flow passing through each detector element and $3 / 4$ of the flow bypassing the detector. The flow splitting is effected by different lengths of 7-mil (0.007-in.) i.d. capillary tubing in the parallel flow paths. Flow splitting increases the detector sensitivity by decreasing the gas flow through the detector. Capillary tubing is also placed on the exit side of the detector to aid in controlling flow variations through the detector. The total carrier gas flow is then recombined for disposal to the Effluent Removal System via a backflow regulator and vacuum pump. Not shown in Figure 1 are the electronic controls for the detector, an electronic siynal integrator, and a recorder for visual display of the detector output. These units are shown in the photograph of Figure 4 . 


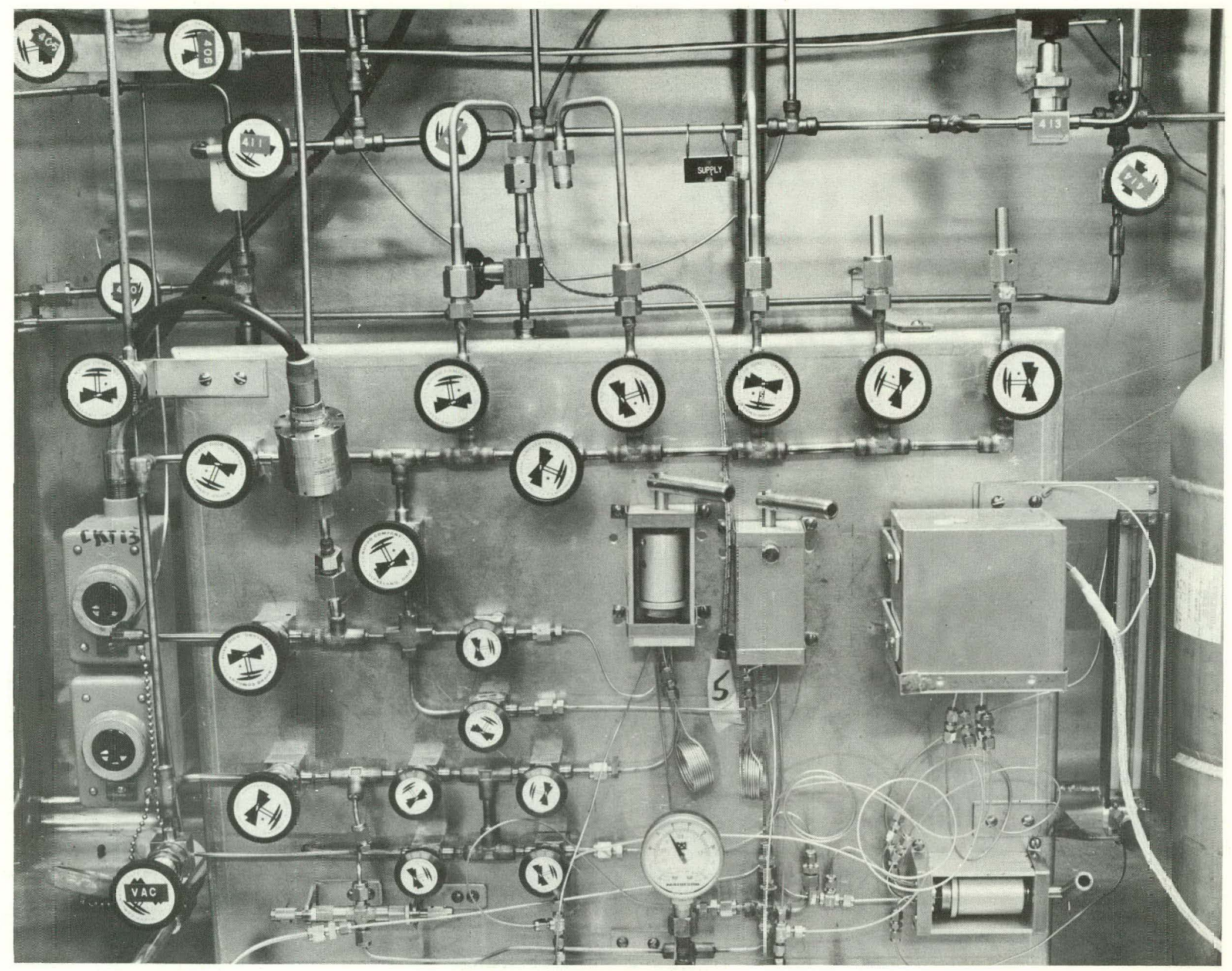

FIGURE 2 - Photograph of gas chromatograph manifold inside glovebox. 


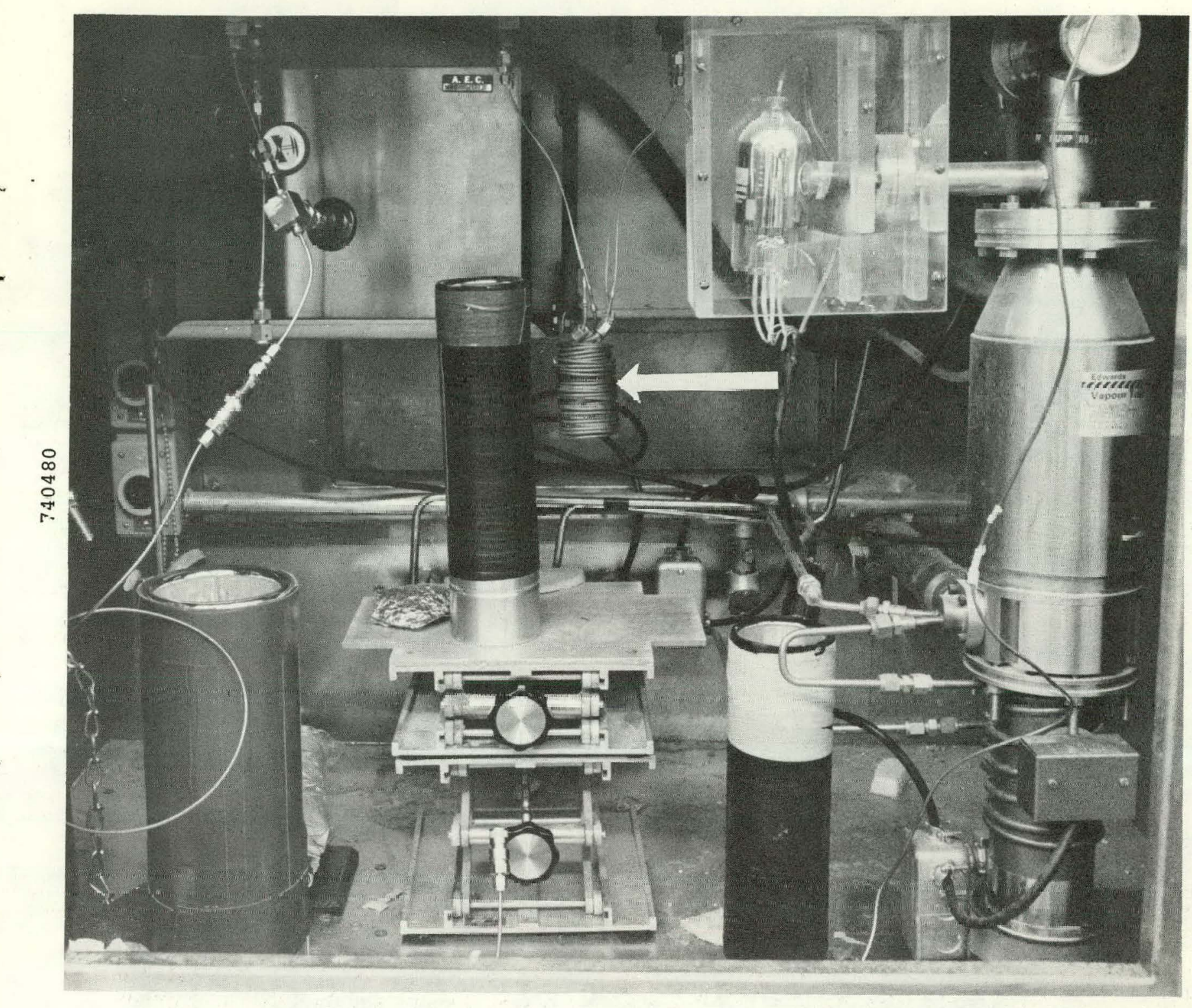

FIGURE 3 - Coiled analytical columns below glovebox. 


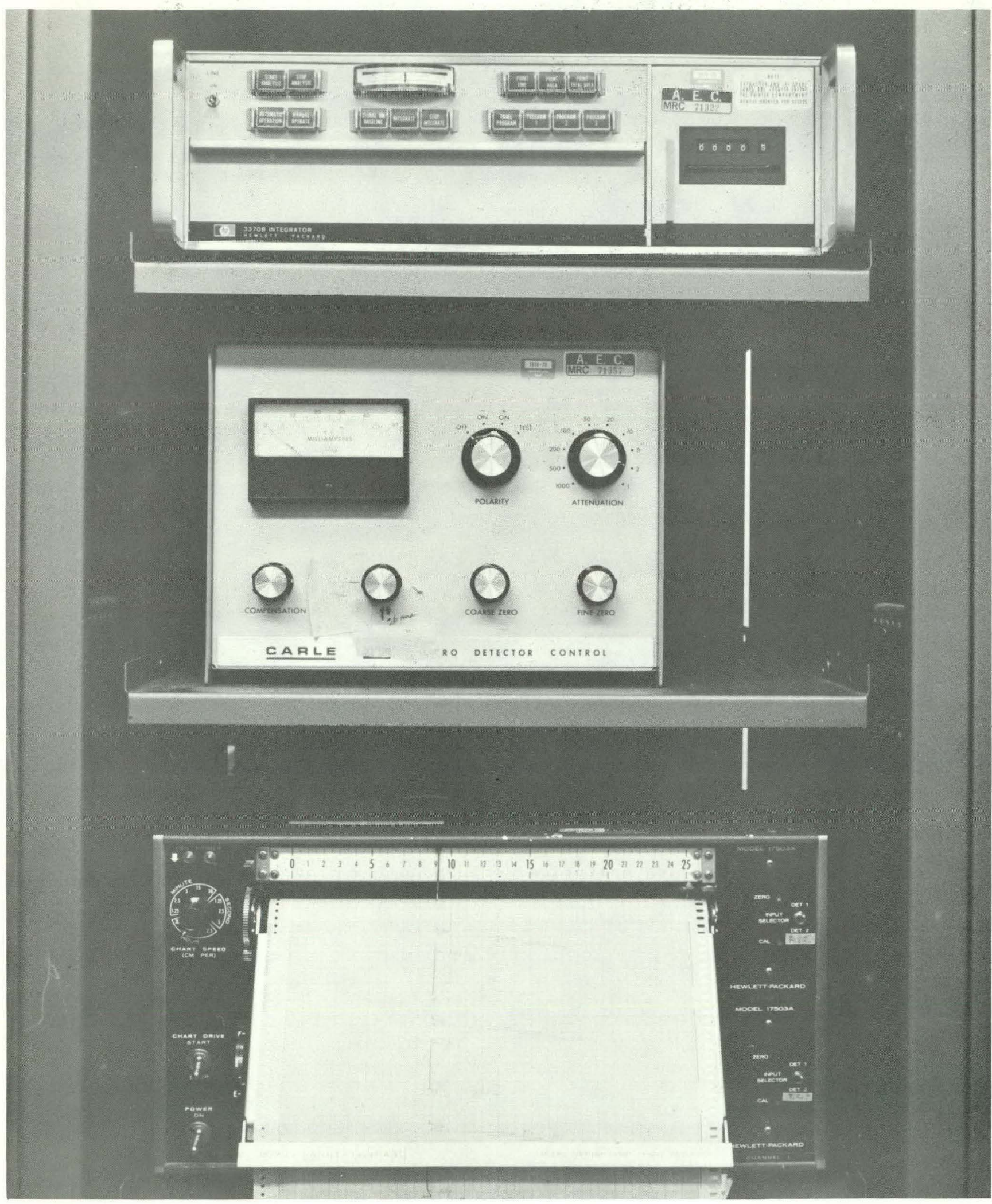

ป

FIGURE 4 - Photograph of chromatograph detector and electrical readout. 


\section{B. SAMPLING SYSTEM}

The sampling manifold of the chromatograph was designed to accommodate a variety of sample sources and to supply both gas sampling valves from all sources. Figure 5 is a complete diagram of the gas sampling manifold and may be readily related to the photograph of the system hardware (Figure 2). The entire sampling manifold is accessible to the vacuum system in the boxline or to the U-Bed through other lines within the boxline.

\section{DESIGN FEATURES}

\section{TIE-IN TO EFFLUENT RECOVERY SYSTEM}

On commercially constructed gas chromatographs, the carrier gas is generally vented from the detector directly into a room atmosphere or a fume hood. However, since the carrier gas effluent of this instrument would contain tritium, disposal of the carrier gas to a laboratory Effluent Recovery system (ERS) was necessary. The interfacing of the ERS and the chromatograph constituted a problem in system design that is described here.

One absolute requirement for operating the gas chromatograph is that the pressure at the instrument "outlet" must be constant; variations in outlet pressure are immediately sensed by the detector, and detector baseline instability is the result. The initial direct interface with the ERS did not provide this constant pressure. The ERS services a large area with a negative pressure of nominally $-3 \mathrm{~mm} \mathrm{Hg}$, and every pressureflow excursion experienced by the ERS was reflected in the chromatograph detector baseline. In order to isolate the gas chromatograph from the ERS fluctuations, a vacuum pump and backflow regulator were placed between the ERS and the instrument detector as shown in Figure 6 . The function of the vacuum pump was to create an insulating partial vacuum between the detector outlet and the pump, thus completely isolating the instrument from the ERS. The backflow regulator was then necessary to control the carrier gas output into the partial vacuum, or stated differently, to maintain a constant positive pressure on the detector side of the backflow regulator by limiting the outflow of gas. These components very effectively isolated the detector from ERS flow excursions.

\section{COPPER VS. STAINLESSS STEEL COLUMNS}

During the investigation of column parameters for the isotopic separation, anomalous behavior was observed in the quality of separation even though the columns of copper and stainless steel (type 304) tubing were identical in packing, length, diameter, and column temperature. Whereas

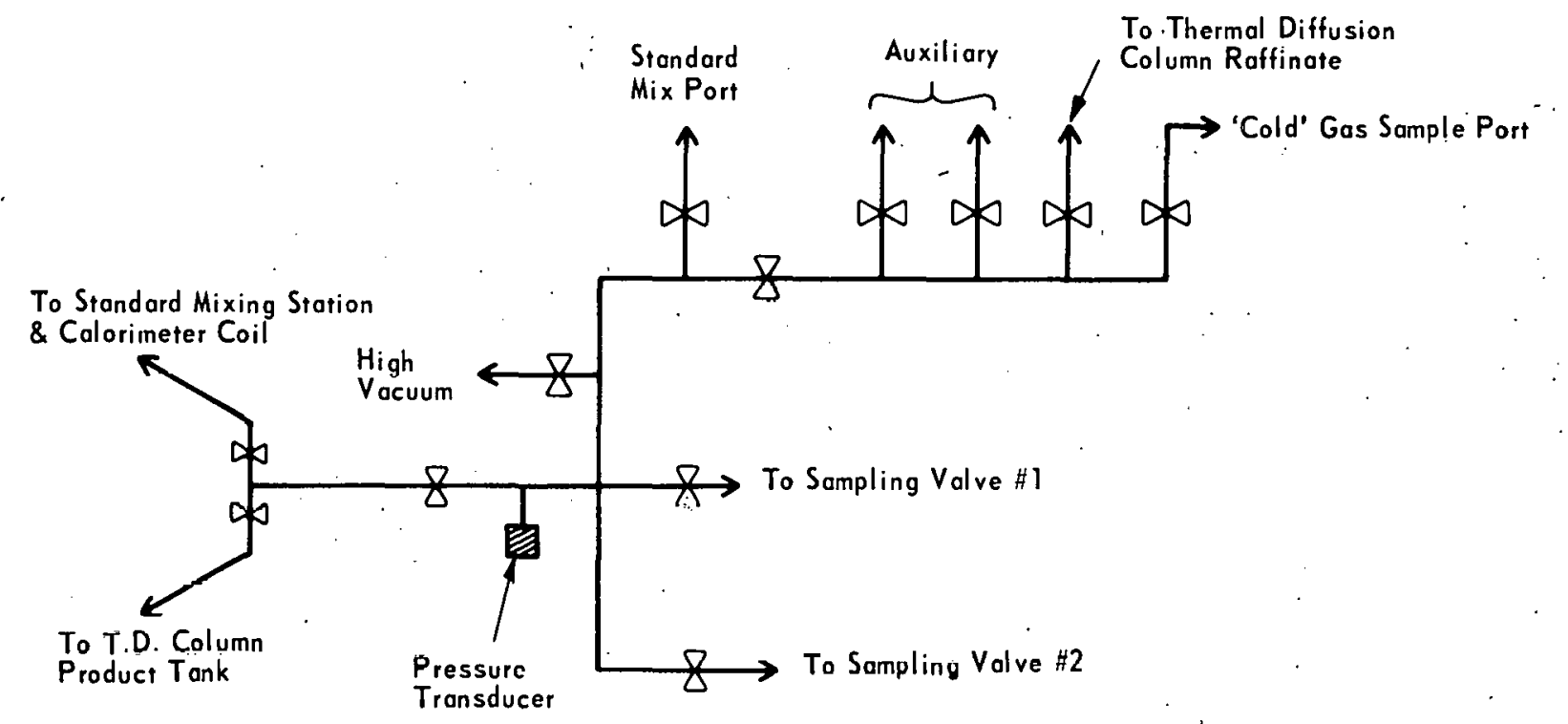

FIGURE 5 - Instrument sampling manifolds. 


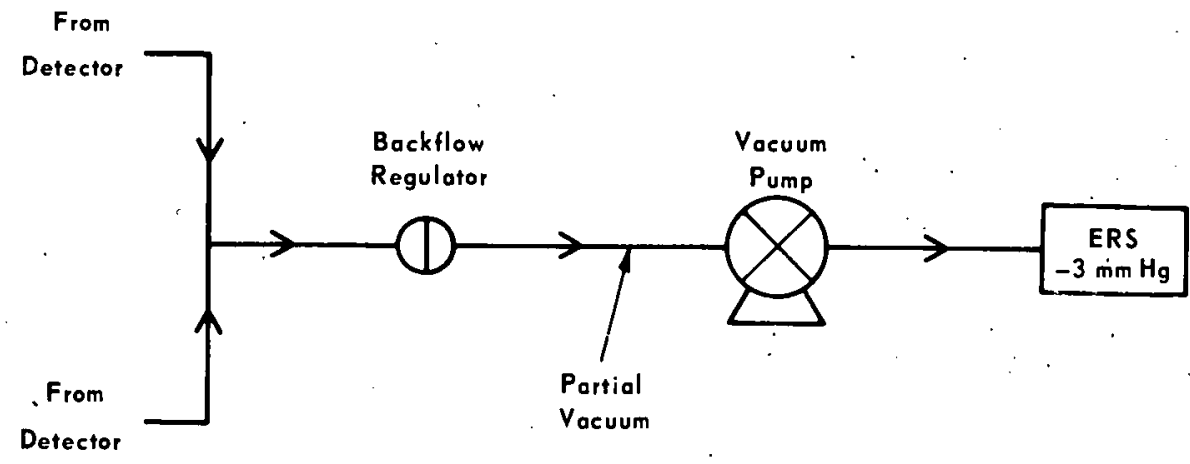

FIGURE 6 - Isolation of instrument detector from. effluent recovery system.

the copper columns effected good separations with symmetrical peaks and reasonable retention times, the stainless steel columns yielded results ranging from total adsorption of the sample to skewed, unseparated peaks with retention times of $30 \mathrm{~min}$ or longer. Apparently, the procedure (see Section E, Key Factors) used for saturating "active" adsorption sites within the columns was not as effective in stainless steel columns as in the copper columns. Further experiments to substantiate this interpretation were not performed; however, copper columns are presently considered a design feature necessary for the success of the isotopic separation.

\section{WELDED CONSTRUCTION}

With one exception, all pipe junctions were either welded or mechanical (Swagelok, Cajon VCR).* Silver solder joints were not used because the silver solder and the solder flux would have been a major source of hydrogen as water or other hydrogen-containing compound and would have contributed greatly to the production of HT in tritium-containing gases by isotöpic exchange. Welding was therefore used in preference to soldering to eliminate this source of hydrogen contamination in samples containing tritium.

*Silver soldering was used, however, to connect the $1 / 8-i n$. o.d. copper columns to $1 / 16-i n$. stainless steel connector lines. Welding these junctions was not possible, and mechanical fittings were inadvisable because of the location.

\section{SYSTEM OPERATION}

Some of the operating conditions and materials are listed in Table 2. As indicated by the differences in the two columns, the isotope separation and the permanent gas separation are necessarily two individual experimental procedures; i.e., they cannot be performed simultaneously. Helium-4, the carrier gas most commonly used in gas chromatography, is the carrier gas for the argon, nitrogen separation. For the isotope separation, however, neon gas is required for the following reasons:

a. The thermal conductivity differential between the neon and hydrogen isotopic gases is substantially greater than the differential between helium-4 and the isotopie yases, thus providiiny a higher detection sensitivity toward the isotopes in neon carrier gas.

b. The neon gas is not adsorbed onto the alumina packing.

c. The diffusion coefficient of neon in hydrogen is less than that of neon in helium.

d. The use of neon permits the determination of helium-3.

The colum temperature. is ambient for the permanent gas separation, but liquid nitrogen temperature is required for the isotopic separation. The column lengths, diameters, and packing sizes are identical for the two columns in order to equalize carrier gas flow through them. 
Table 2

CHROMATOGRAPHIC MATERIALS AND OPERATING CONDITIONS

$\begin{array}{lcc} & \begin{array}{c}\text { Ar, } \mathrm{N}_{2} \\ \text { Separation }\end{array} & \begin{array}{c}\text { Isotope } \\ \text { Separation }\end{array} \\ \text { Carrier Gas } & { }^{4} \mathrm{He} & \mathrm{Ne} \\ \text { Flow Rate (Est.) } & 50-60 \mathrm{~cm}^{3} / \mathrm{min} & 40-45 \mathrm{~cm}^{3} / \mathrm{min} \\ \text { Column Temperature } & 23^{\circ} \mathrm{C} & -196^{\circ} \mathrm{C} \\ \text { Column Length } & 3.5 \text { meters } & 3.5 \text { meters } \\ \text { Column Diameter } & 2 \mathrm{~mm} \mathrm{i.d.} & 2 \mathrm{~mm} \mathrm{i.d.} \\ \text { Column Packing } & 80 / 100 \text { Molecular } & 80 / 100 \mathrm{Alumina} \\ & \text { Sieves 5A } & \end{array}$

Two examples of analyses routinely performed by the chromatograph are illustrated in Figures 7 and 8 . Figure 7 is a chromatogram obtained from a determination of helium-3, HT, and DT impurities in tritium. The vertical scale of the chromatogram is logarithmic, so peak areas are not representative of the true relative concentrations. Figure 8 is a chromatogram of a standard gas mixture of helium, deuterium, and tritium, and the protium impurities HD and HT. The HD and HT impurity peaks are well separated from the massive deuterium and DT peaks. The vertical scale is logarithmic to maintain all peaks on the recorder scale.
The retention times of the impurity gases are shown in Figures 7 and 8 . These retention times are for a specific set of instrument operating conditions as contained in the Standard Analytical procedures. This qualifying statement is necessary because the isotopic retention times are highly dependent upon carrier gas flow rate, the amount of alumina deactivation, and also sample composition and size. The dependence upon sample composition is illustrated by comparing the retention time of $\mathrm{HT}$ in the two different sample types of Figures 7 and 8 . It is evident that knowledge of sample history and composition are necessary to obtain the correct interpretation of isotopic chromatograms. The

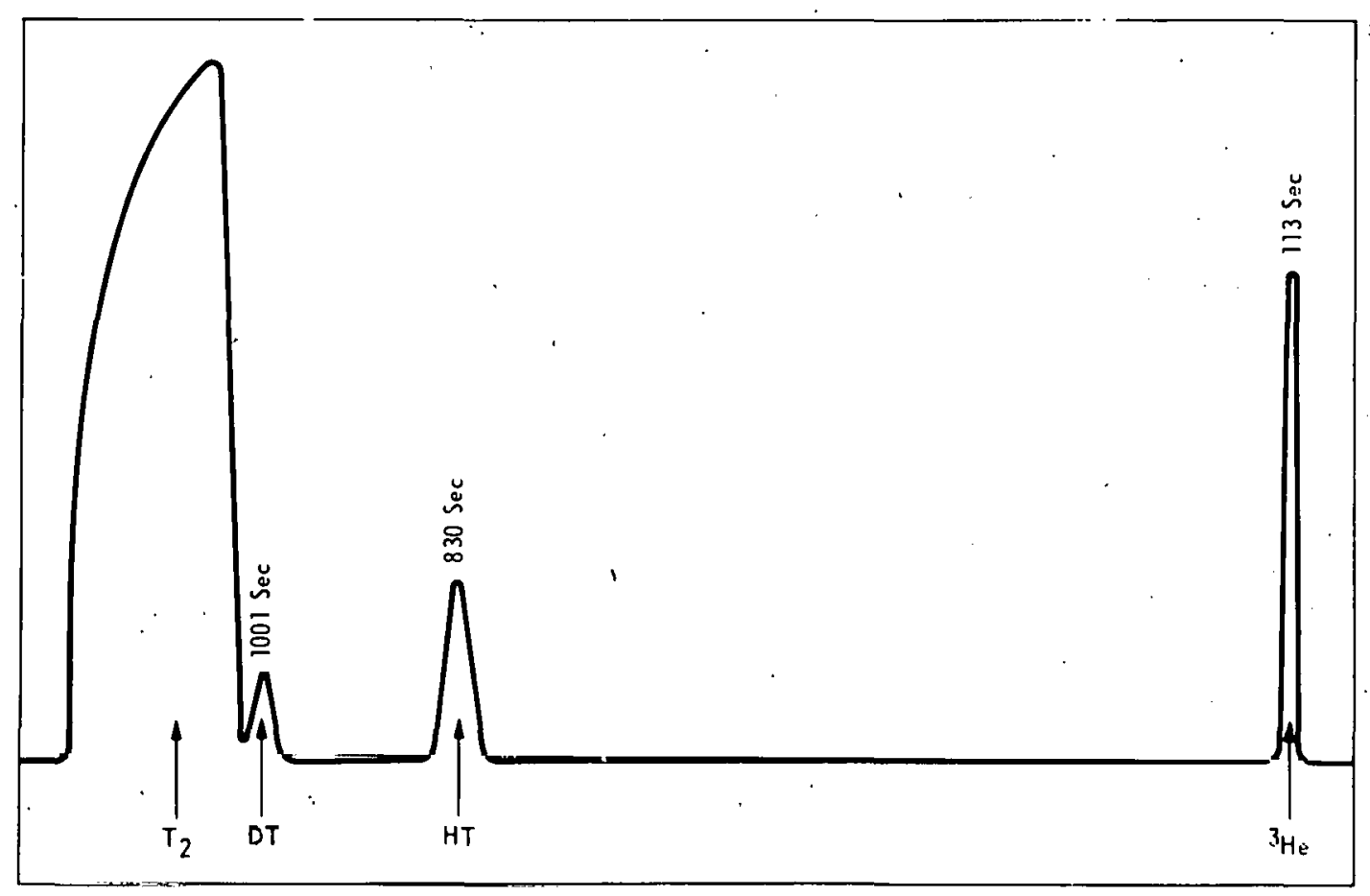

FIGURE 7 - Chromatogram of helium-3, HT, and DT

in tritium. 


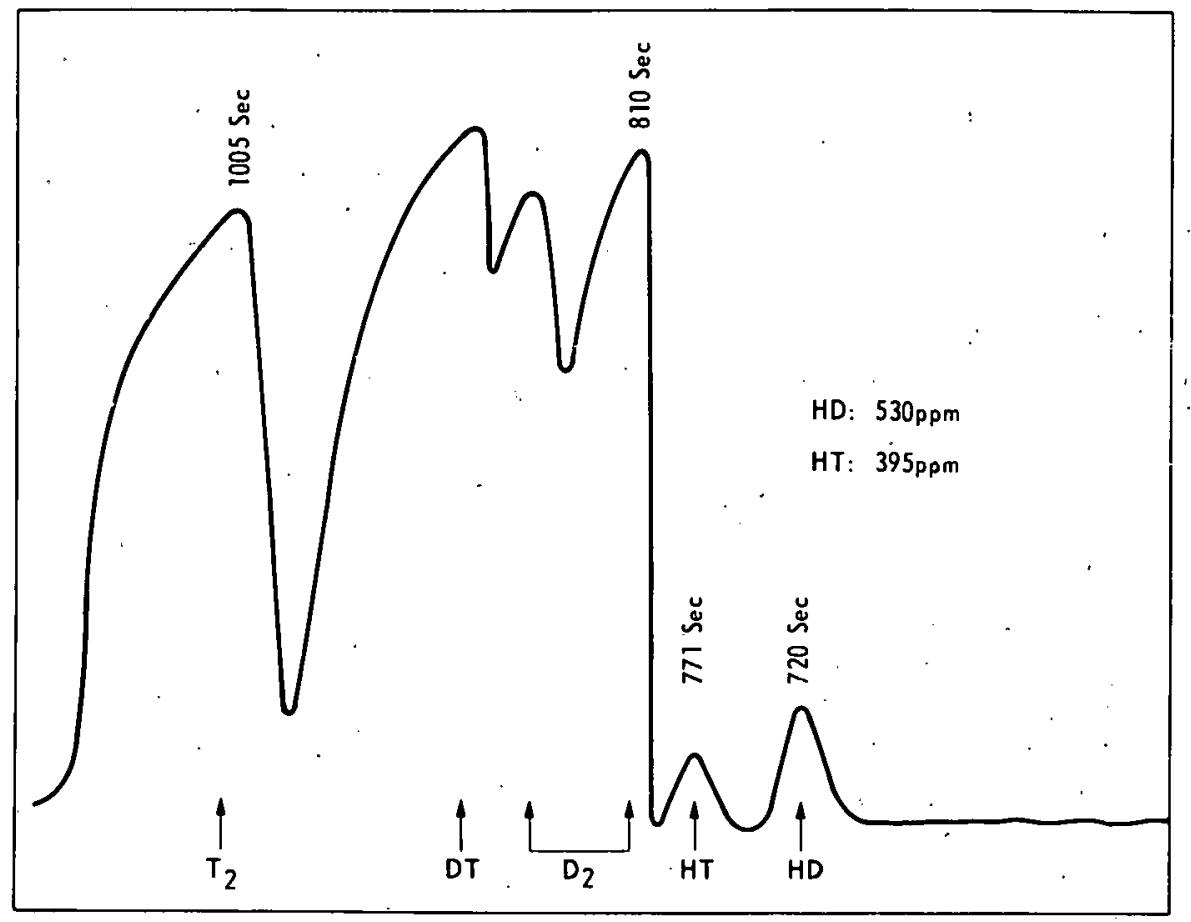

FIGURE 8 - Chromatogram of HD and HT in a deuteriumtritium mix.

retention times of the permanent gases are dependent also upon operating conditions, but are not subject to variability caused by differences in composition.

\section{E. KEY FACTORS}

In this section emphasis is placed upon the key factors which are essential for the analytical. sensitivity and isotopic separation capabilities of the instrument.

\section{SENSITIVITY}

The sensitivity of the instrument is dependent, of course, on the detector. type (thermistor) and its internal volume, but is also highly dependent upon the constancy of carrier gas flow and flow rate through the detector cells, and upon the variability of detector cell temperature. The hardware in the instrument which contributes to maintaining constant gas flow through the chromatograph is noted below:

- Carrier gas inlet pressure regulation by a two-stage regulator with metal diaphragms.

- Resistance to flow by the $3 \frac{1}{2}-m$ columns. vibration packed with $80 / 100$ mesh material.
- Resistance to flow and flow rate change. by the 7-mil i.d. capillary lines between the columns and detector inlet, and also between the detector outlet and backflow regulator.

- Resistance to flow change by the backfluw reyulator.

In addition to this hardware, detector sensitivity is enhanced by splitting the carrier gas flow at the detector (see Figure 1) to allow only a fraction of the gas flow to enter the detector.

\section{ISOTOPE SEPARATION}

The key factor in the isotopic separation is the extent of "saturation" of the active adsorption sites on the alumina packing. The saturation (or deactivation) procedure involves filling the column with nitrogen gas to $40 \mathrm{psig}$, isolating the column by closing bellows valves, and then immersing the column in liquid nitrogen. This lowering of temperature causes selective adsorption of. the nitrogen gas on the active adsorption sites and allows the isotopic separation equilibrium to proceed without excessive adsorption on the alumina to cause long retention times. After the columns are chilled, neon carrier gas is admitted to the column. Carbon dioxide has also been used as a deactivation gas, but nitrogen is simpler to work 
with in that local freezing (the effect being to plug the column) is less likely with nitrogen. The volume of nitrogen gas available for active site saturation is about $125 \mathrm{~cm}^{3}$ (STP) for both columns, or, if the distribution is equal between the columns, roughly $65-70 \mathrm{~cm}^{3}$ (STP) of nitrogen effects the saturation of the $3.5-\mathrm{m}$ length of. $80 / 100$ mesh alumina packing.' Wide latitude from this volume of deactivation gas produced acceptable separations, but in general an excessive amount of deactivation gas (e.g. $500 \mathrm{~cm}^{3}$ ) degraded the separation quality, and smaller amounts of nitrogen (e.g. $50 \mathrm{~cm}^{3}$ ) increased the retention times significantly.

\section{System Calibration}

\section{A. PRESSURE TRANSDUCER}

Two pressure transducers were used in the system to measure sample pressures. The original transducer had a range of $0-2700 \mathrm{~mm} \mathrm{Hg}$ and was replaced with a $0-800 \mathrm{~mm} \mathrm{Hg}$ transducer. The $800-\mathrm{mm}$ unit was placed in the instrument to match the transducer working range more closely with actual sample pressures. Both transducers and the associated electronic. drive and readout units were calibrated and certified by the Mound Standards Laboratory. Calibration data are presented in Table 9.

\section{B. CALIBRATION GASES}

Information about the standard gases used for calibrating the gas chromatograph is shown in Table 3. The gas mixtures purchased from the vendor were sampled by mass spectrometry to verify the approximate concentrations of the gases; gas chromatography was the technique used by the vendor to establish the argon and nitrogen concentrations. The error values for these standards were stated by the vendor to be a summation of instrument inaccuracy $(1 \%)$ and sampling reproducibility error (1\%). The first set of standards purchased was in a hydrogen matrix; the second set was prepared in a helium-4 matrix. The reason for the choice of hydrogen in the first set was to approximate as nearly as possible the composition of actual samples. The replacement of hydrogen by helium-4 was necessary to preclude or prevent a buildup of exchangeable hydrogen in the instrument surfaces during recalibrations.

The helium-3 and HD calibration gases were prepared at Mound Laboratory in a standard gas mixing manifold, and the compositions were determined by partial pressure measurements. All pressure measurements were performed with Wallace-Tiernan gauges with an accuracy of $\pm 0.05 \%$ of full scale.

Table 3

SOURCF, PREPARATION, AND RELIABILITY OF CALIBRATION GASES

\begin{tabular}{|c|c|c|c|c|c|}
\hline Component & $\begin{array}{l}\text { Matrix } \\
\text { Gas } \\
\end{array}$ & $\begin{array}{c}\text { Nominal } \\
\text { Concentration } \\
(\%)\end{array}$ & $\begin{array}{c}\text { Error } \\
(\%) \\
\end{array}$ & & $\begin{array}{l}\text { eparation } \\
\text { Source }\end{array}$ \\
\hline$A x$ & $\mathrm{H}_{2,},{ }^{4} \mathrm{He}^{\mathrm{a}}$ & 0.2 & \pm 2 & Air & Products \\
\hline $\mathrm{N}_{2}$ & $\mathrm{H}_{2},{ }^{4} \mathrm{He}^{\mathrm{a}}$ & 0.2 & \pm 2 & Air & Products \\
\hline${ }^{3} \mathrm{He}^{\mathrm{b}}$ & $\mathrm{Ne}^{\mathrm{b}}$ & 0.2 & \pm 1 & & Mound \\
\hline $\mathrm{HD}^{\mathrm{b}}$ & $\mathrm{Ne}^{\mathrm{b}}$ & $1.0,0.8$ & \pm 1 & & Mound \\
\hline HT & $\mathrm{Ne}$ & 1.0 & \pm 1 & & Mound \\
\hline DT & $\mathrm{Ne}$ & 1.0 & \pm 1 & & Mound \\
\hline
\end{tabular}

${ }^{a}$ Argon and nitrogen were prepared as one mixture of standards. The matrix of the first standard set was hydrogen, and helium-4 was the matrix of the second set.

${ }^{b}$ Helium-3 and HD were combined into one caljbration mixture. 
The HT and DT caliuration gas preparation at Mound Laboratory was more complex. Equimolar amounts of hydrogen and tritium and also of deuterium and tritium were mixed to prepare two stock mixtures of HT and DT by the exchange reactions (1) and (2).

$$
\begin{aligned}
& \text { (I) } \mathrm{H}_{2}+\mathrm{T}_{2}=2 \mathrm{HT} \mathrm{K}_{\mathrm{eq}}=2.58(300 \mathrm{~K}) \\
& \text { (2) } \mathrm{D}_{2}+\mathrm{T}_{2}=2 \mathrm{DT} \mathrm{K}_{\mathrm{eq}}=3.82(300 \mathrm{~K})
\end{aligned}
$$

After the concentrations of the principal isotopic species in each mixture were determined by mass spectrometry, the mixtures were diluted with neon to obtain 18 concentrations of $\mathrm{HT}$ and DT. Samples of the final mixtures were radiocounted for total tritium as a crosscheck to the standard mixing procedure. These standards also provided a source of calibration for hydrogen, deuterium, and tritium since the concentrations of these species were known in the diluted standards. Pressure measurements in the HT and DT mixing procedures were with Ruska instrumentation, with an error of $0.05 \%$ of the reading plus $0.015 \%$ of full scale.

\section{SYSTEM CALIBRATION PROCEDURE}

The general method of calibrating the instrument is outlined below:

a. A standard calibration gas mixture was prepared for each gas species (HT, DT, argon, etc.) as described in the previous section.

b. For each gas standard, data were acquired for integrated detector response as a function of samplc pressure at constant sample volume over a pressure range of $25-400 \mathrm{~mm}$.

c. The linear-least-squares mathematical technique was used to derive the relationship between detector response and standard gas pressure for each impurity species.

From the linear calibration lines computed in (c), concentrations of actual samples are computed. This calibration technique differs from more common techniques only in the method of delivering known moles of gas component to the detector. Essentially, this method delivers a desired mass of, say, HT to the detector by varying the sample pressure, with sample volume and concentration being constant; a more common method would be to vary the concentration (i.e. have several standards) and sample these concentrations at constant pressure and volume.
The reason. for choosing this calibration method lay principally in the stability or instability of the standards containing tritium at low concentrations. The concentration range of interest is $100-2000 \mathrm{ppm}$, and a guarantee could not be made for stable concentrations of isotopes at these levels in terms of hydrogen ingrowth by exchange. Therefore, rather than prepare several standards of questionable value over this concentration range, one standard of higher stability was prepared at the $1 \%$ level of HT and DT, and a range of concentrations was simulated by varying. the sample pressure. This calibration design was extended to all impurity gas standards to attain uniformity in the experimental procedure.

\section{METHOD OF COMPUTING RESULTS}

The experimental data that are necessary for computing concentration results are the following:

a. The concentration in parts per million of the standard gas used to prepare the calibration line.

b. The integrated detector response (counts) for the standard gas at the pressure at which the "unknown" sample is run. This value is calculated from the calibration line equation.

c. The integrated detector response (counts). for the "unknown" sample component.

With these data, the "unknown" concentration is then complited from the following equation:

$$
\text { conc. }(\text { unk })=\text { conc. }(\text { std }) \times \frac{\text { counts (unk) }}{\text { counts }(\text { std) }}
$$

Example - A standard calibration for $\mathrm{HT}$ was performed with a 10,000 ppm (18) HT standard. The linear-least-squares equation for this calibration was:

$$
\begin{aligned}
\text { counts }(\text { std })= & (50.258)(\text { pressure })- \\
& 40.26 .
\end{aligned}
$$

An "unknown" sample containing HT was determined experimentally to give 110 counts of HT at a sample pressure of $221.2 \mathrm{~mm} \mathrm{Hg}$. The calculation of the "unknown" HT concentration uses the following data:

a. Standard HT concentration: 10,000 ppm

b. Standard HT counts: 11,077 (from the calibration equation using $221.2 \mathrm{~mm}$ pressure). 

c. "Unknown" HT counts: 110 counts (at
$221.2 \mathrm{~mm}$ pressure)
The calculation is:

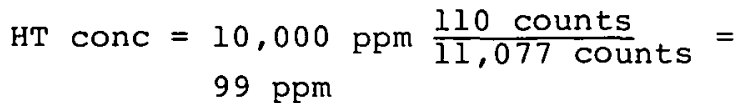

\section{System Reliability: Method Performance}

\section{A. PRECISION}

\section{ANALYSIS OF VARIANCE}

Analysis of variance experiments were performed to establish the random variability of the chromatographic system, and the experiments included all the impurity gases except HD. The standard gases used for obtaining calibration data were also used for the analysis of variance (ANOVA) experiments. The experimental design was to determine all five gases (argon, nitrogen, helium-3, HT, DT) on the same day and to perform this experiment at approximately twiceweekly intervals for a total of six days. A seventh day, however, was added to the HT and DT data. More precisely, the intent of the ANOVA experiments was to obtain a measurement of the relative standard deviation (precision) of the chromatographic method and to establish a comparison of the within-day and between-day variability of the system.
The raw data from the ANOVA experiments are presented in Table 4 , and the results of the statistical analysis are shown in Tables 5 and 6 . Table 5 shows the relative standard deviation of the between-day, within-day, and total variability for each gas. The HT and DT results are separated from the others because of the concentration difference. These results, along with the F-ratio test results in Table 6 indicate that the between-day variability is the principal contributor to the precision or ralldom error component. The comparison of the calculated F-ratio and the table Fratio accentuates the significance of the larger between-day variability. Also indicated in the Table 5 results is the significant relative or absolute difference between the total variability of the two concentration levels. This concentration dependence most likely is a reflection of relatively smaller peak integration counting error as the chromatographic peaks become larger.

Table 4

GAS ANALYSIS DATA OBTAINED FROM ANALYSIS OF VARIANCE EXPERIMENT

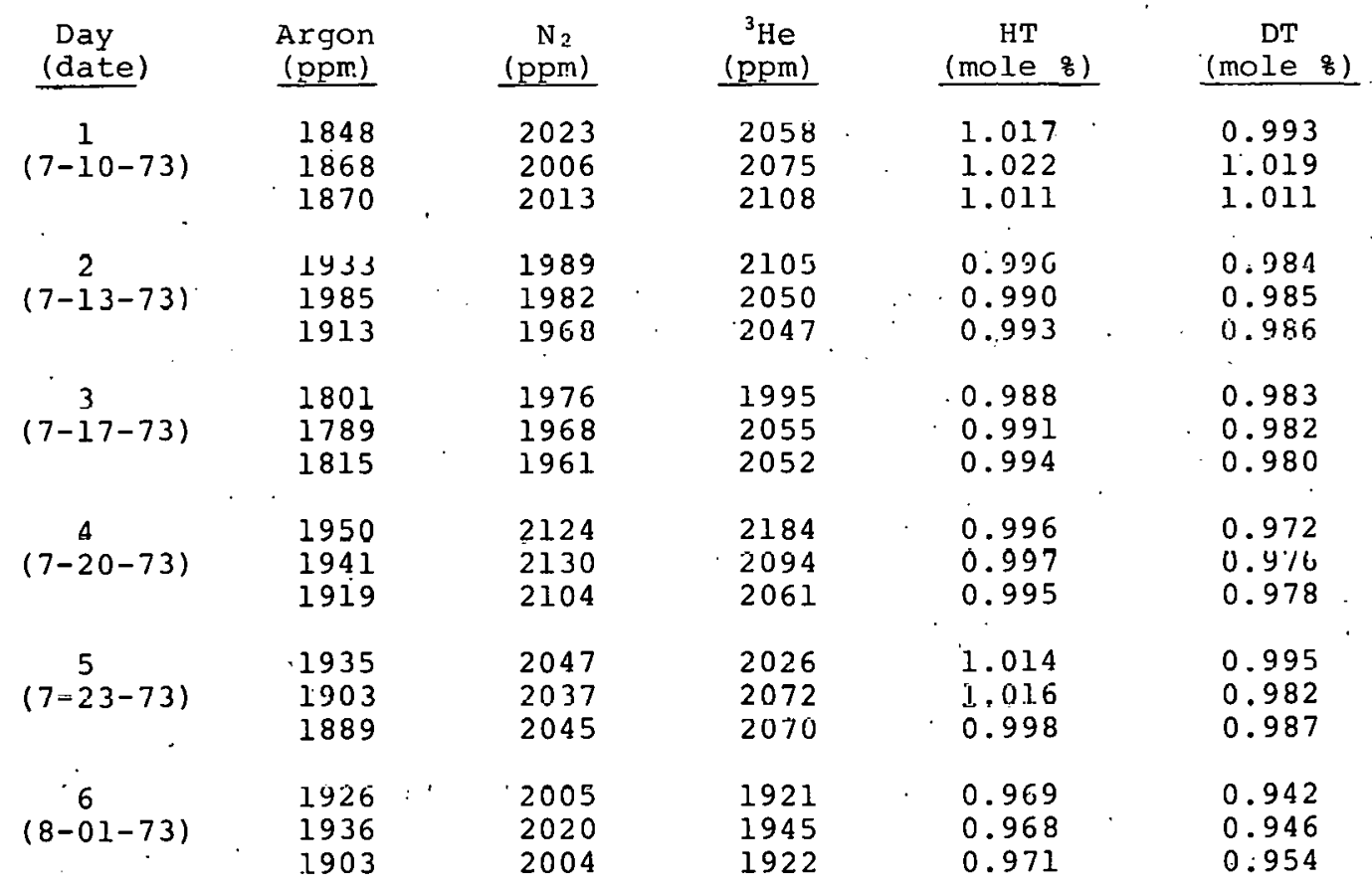


Table 5

VARIABILITY RESULTS FROM THE ANOVA EXPERIMENTS

\section{Precision Component}

Within Day o

Between Day o

TOTAL $\sigma(8)$

\section{Concentration $=0.28$}

Ar

1.1

$$
\underline{\mathrm{N}_{2}}
$$$$
{ }^{3} \mathrm{He}
$$

2.2

0.5

1.8

2.1

2.4

2.9

2.6

3.2

Table 6

ANOVA SUMMARY TABLE

\section{Factors}

Between

$\mathrm{N}_{2}$ Within

Between

${ }^{3} \mathrm{He}$ Within

Between

HT

Within

Between

DT
Ar Within

\section{Sum of}

Squares

5591

44425

1075

44407

15660

59530

$2.98 \times 10^{-4}$

Between
$4.05 \times 10^{-3}{ }^{3}$

$5.41 \times 10^{-4}$
$0.58 \times 10^{-2}$

\section{Degrees of Freedom}

12

5

12

5

12

5

12

5

12

5
Mean

Squares

465.9

8884.9

89.6

8881.4

1304.8

11906.1

$0.2483 \times 10^{-4}$.

$0.8099 \times 10^{-3}$

$0.4505 \times 10^{-4}$

$0.1165 \times 10^{-?}$
Concentration $=1.0 \%$

$\begin{array}{ll}\text { HT } & \text { DT } \\ 0.5 & 0.7 \\ 1.3 & 1.6 \\ 1.6 & 2.0\end{array}$

\section{ESTIMATION BY PROPAGATION OF ERRORS}

A second method was used to estimate the potential precision error, this method being a statistical propagation of known sources of error. For the chromatographic system, the known and measurable errors were from 1) the production of the calibration curves, 2) the integration of sample peaks (counting error), 3) the measurement of sample. pressures, and 4) the variation of boxlines or system temperature. These sources of error are embodied in the following equation from which the error estimation is calculated:

$$
\frac{\sigma_{c}^{2}(u n k)}{c^{2}(u n k)}=\frac{\sigma_{c}^{2}(s t d)}{c^{2}(s t d)}+\frac{\sigma^{2} \operatorname{counts}(\text { unk })}{\operatorname{counts}^{2}(\text { unk })}+\frac{\sigma_{p}^{2}}{p^{2}}
$$

where $\mathbf{c}=$ concentration, and

$$
\mathrm{p}=\text { pressure }
$$

In this equation, the standard concentration error is calculated from measured pressure readings and the known error of the pressure measuring devices. The counting error is the square root of the number of colints, and the pressure variability is calculated from recorded temperature variations in the glovebox containing the chromatograph.

The counting error from eiectronic integration of chromatographic peaks is the principal known source of precision error. A comparison of the calculated error summations with the experimental analysis of variance total error is shown in Table 7. The agreement between the two sets of data indicates that the major sources of error have been identified and are accounted for in the analysis of variance. For the quotation of precision error, analysis of variance data are used in preference to the propagation of error values since. they are determined experimentally. 
Table 7

COMPARISON OF ANALYSIS OF VARIANCE RESULTS WITH PROPAGATION

OF ERROR RESULTS

\begin{tabular}{|c|c|c|c|c|c|}
\hline & $A \mathrm{x}^{\mathrm{a}}$ & $\underline{\mathrm{N}}^{\mathrm{a}}$ & $\underline{\mathrm{He}^{\mathrm{a}}}$ & $\mathrm{HT}^{\mathrm{b}}$ & $\underline{D T}^{b}$ \\
\hline \multirow{2}{*}{$\begin{array}{l}\text { Analysis of } \\
\text { Variance ( } 8 \text { rel.) }\end{array}$} & 2.9 & 2.6 & $3.2 \ldots$ & 1.6 & 2.0 \\
\hline & & & & & \\
\hline $\begin{array}{l}\text { Propagation of } \\
\text { Errors (\& rel.). }\end{array}$ & 7.7 & 3.0 & 3.3 & 1.2 & 1.6 \\
\hline $\begin{array}{l}\text { avalues obtained fo } \\
\text { (nominal). }\end{array}$ & cono & itra & ons of & 2000 & ppm \\
\hline
\end{tabular}

\section{B. STABILITY OF HT AND DT STANDARD MIXTURES}

Calibration of the instrument system with HT and DT provided unique problems in demonstrating that the standards would remain stable over a period of weeks. The potential for instability occurs because sorbed protium on metal surfaces of holding containers will readily exchange with tritium in standard mixtures. to give a buildup of $H T$ in the mixture over a period of time. Specially treated containers were used to inhibit this isotopic exchange, and relatively high concentrations ( $1 \%$ ) of HT and DT were prepared so that the measurable ingrowth of protium would be small. The basic question, then, concerns the short-term stability of the HT and DT standards so that reuse of the standards may proceed during that period with confidence.

The data used to examine this stability question were extracted from the analysis of variance experiments and are graphically shown in Figures 9 to 15 . The HT standard is illustrated first; the HT concentration forms no discernable trends over a period of 46 days (Figure 9), and similarly the hydrogen and tritium concentrations (Figures 10 and 11 ) do not change systematically over the same time. The DT standard gas, however, did show distinct systematic changes with time. The DT concentration (Figure 12) decreased slightly; similarly, the deuterium and tritium concentrations of the DT standard decreased (Figures 13 and 14). Also, the $\mathrm{HD}+\mathrm{HT}$ concentration sum for the DT standard increased in the time period by several hundred parts per million.
The data from these experiments, especially the DT experiment, must be examined in their proper perspective to avoid erroneous conclusions. The HT standard gas did not show any serious instability over the seven-week period, but a measurable change did occur in the DT standard with all effects presumably being caused by protium ingrowth by exchange. The magnitude of the changes were, however, small in comparison to the magnitude of the DT concentration, and the net change in concentration was not significantly different from the analysis of variance precision error caused by between-day variability. For practical usage over a period of 4-5 weeks, the standards in treated containers were considered to maintain their stability.

\section{INTEGRATION OF OVERLAPPING PEAKS}

One compromise made in designing the twocolumn gas chromatograph with both collumns being functional. was in the choice of column lengths. The design required the lengths of the two columns to be equal in order to provide an equivalent flow of carrier gas through both sides of the detector. The criteria for the choice of column length were: 1) to provide a sufficient length of the alumina to effect a reasonable separation of the isotopes; and 2) at the same time, to provide a short enough length of the molecular sieve column to achieve the permanent gas separation in a reasonable time and with integratable, symmetrical peak shapes. The column length chosen $(3.5 \mathrm{~m})$ satisfied both criteria except for a deficiency in the isotopic separation; i.e., at low concentrations of DT in tritium a degree of overlapping of the two $u_{\mathfrak{r}}$ 


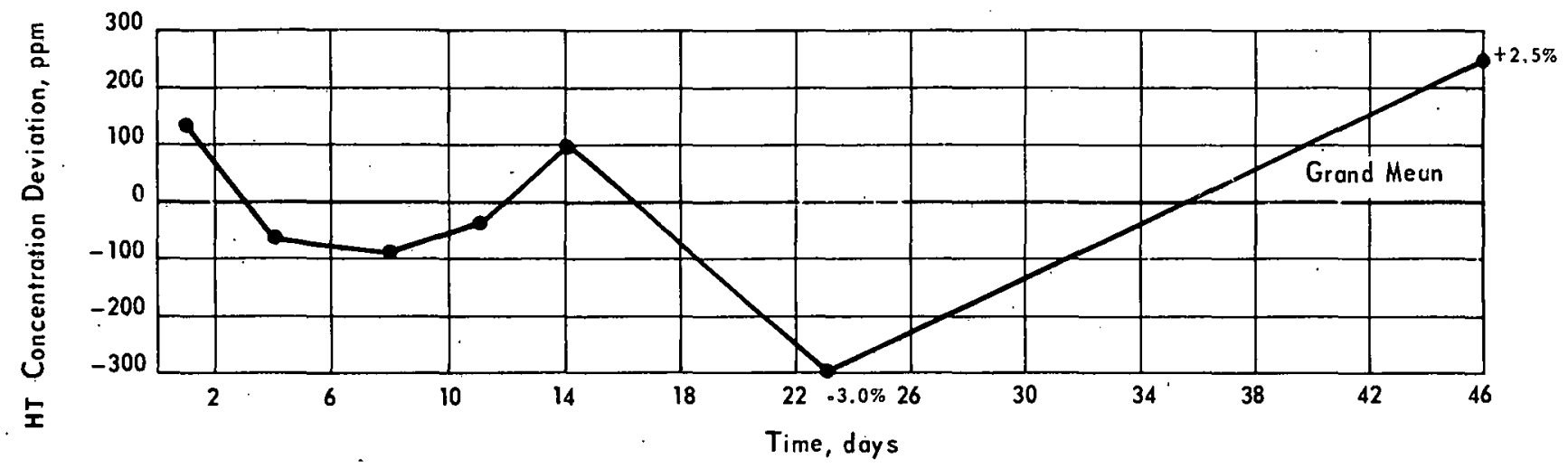

FIGURE 9 - Deviation of HT daily means from grand mean ( $1 \%$ HT standard).

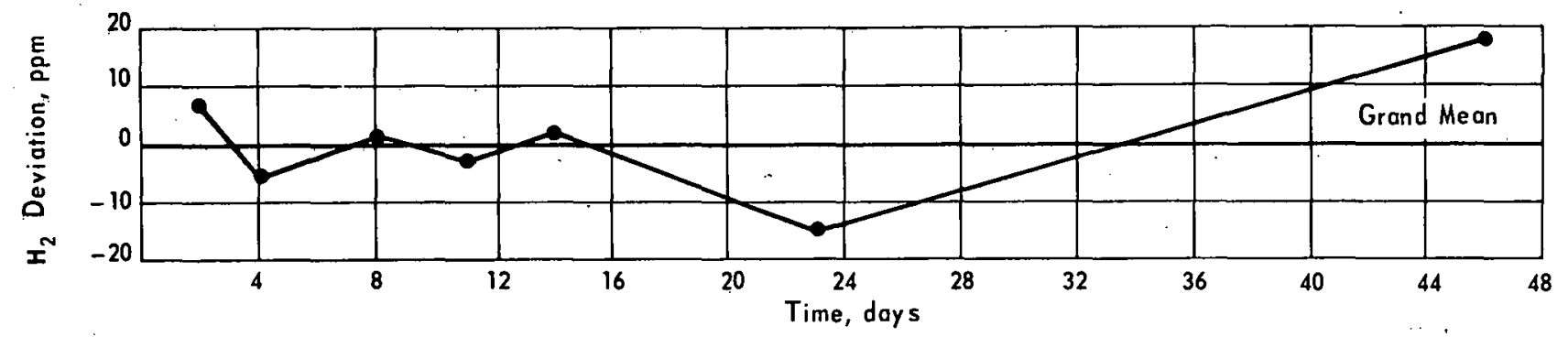

FIGURE 10 - Deviation of hydrogen daily means from grand mean $(1 \% H T$ standard).

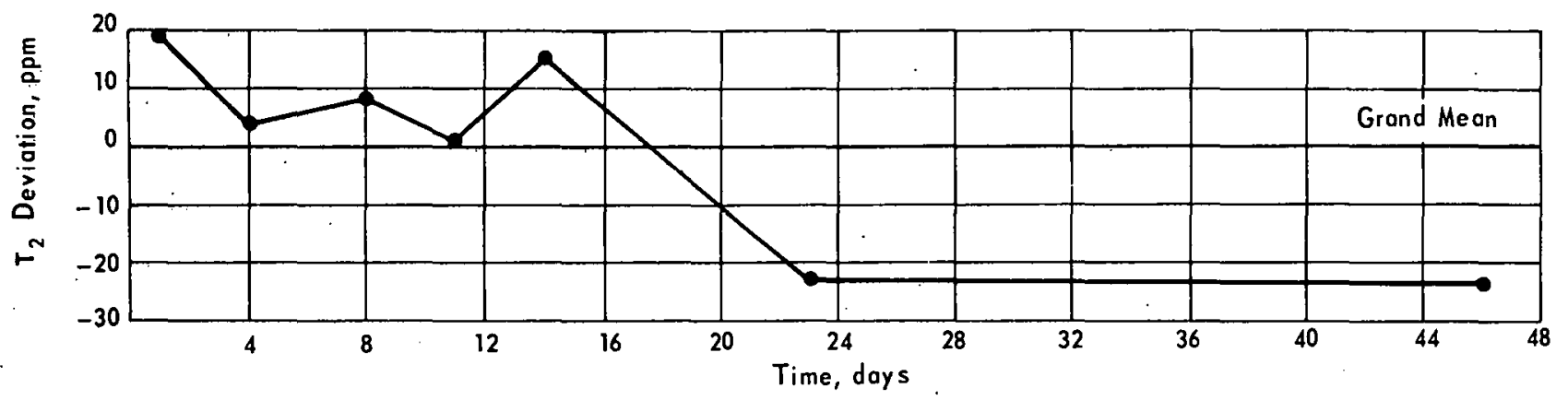

FIGURE 11 - Deviation of tritium daily means from grand mean (1\% HT standard). 


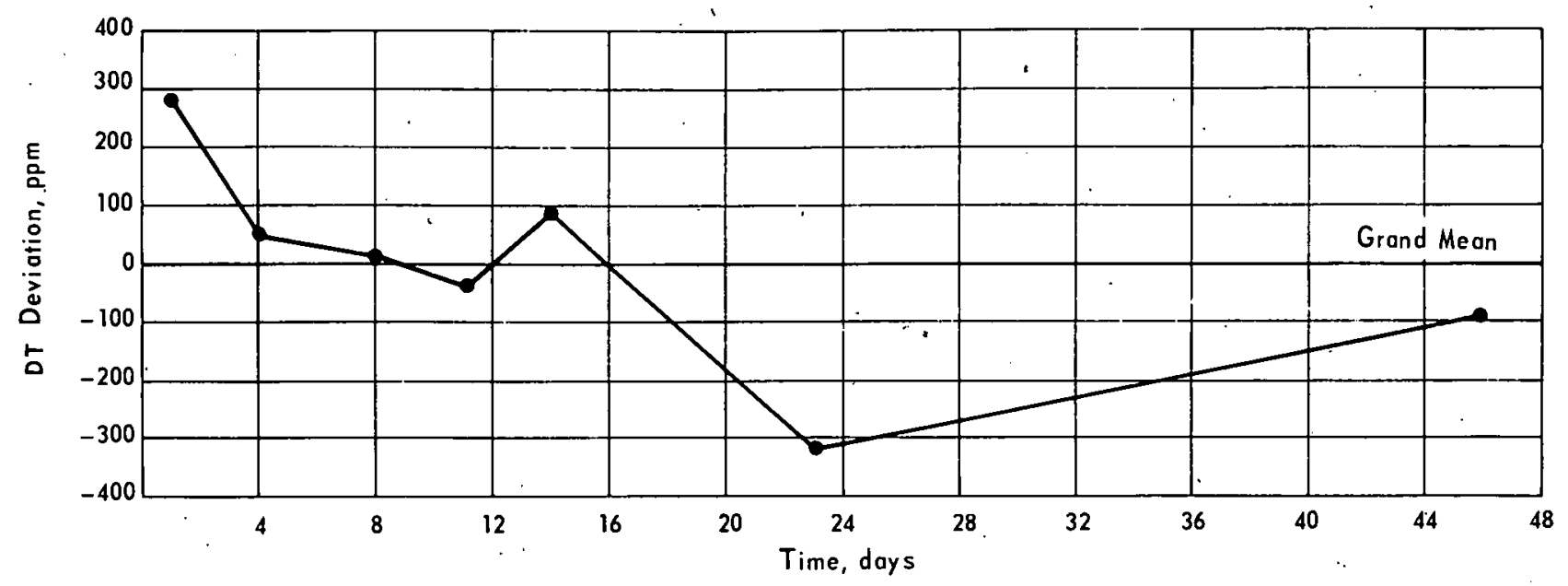

FIGURE 12 - Deviation of DT daily means from grand mean (1\% DT standard).

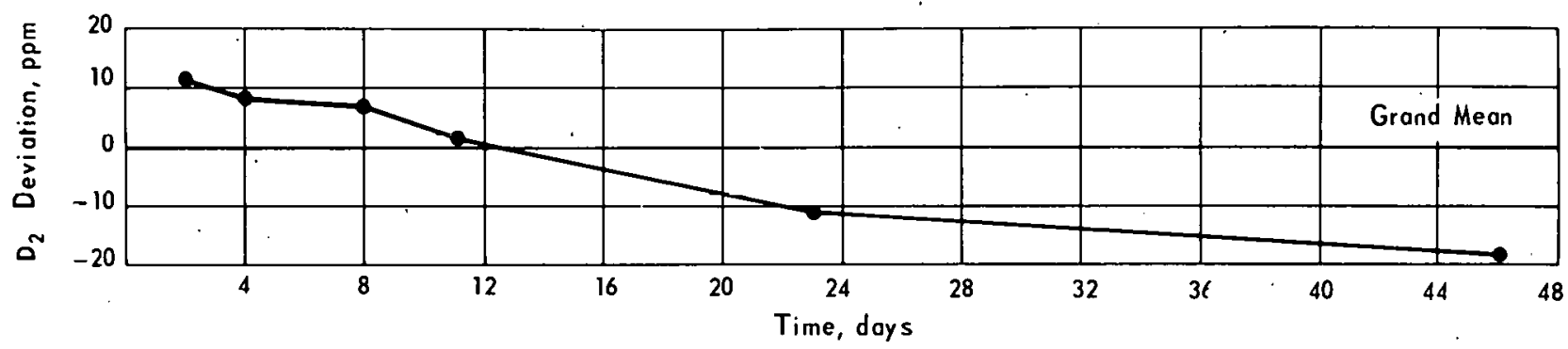

FIGURE 13 - Deviation of deuterium daily means from grand mean (1\% DT itandard).

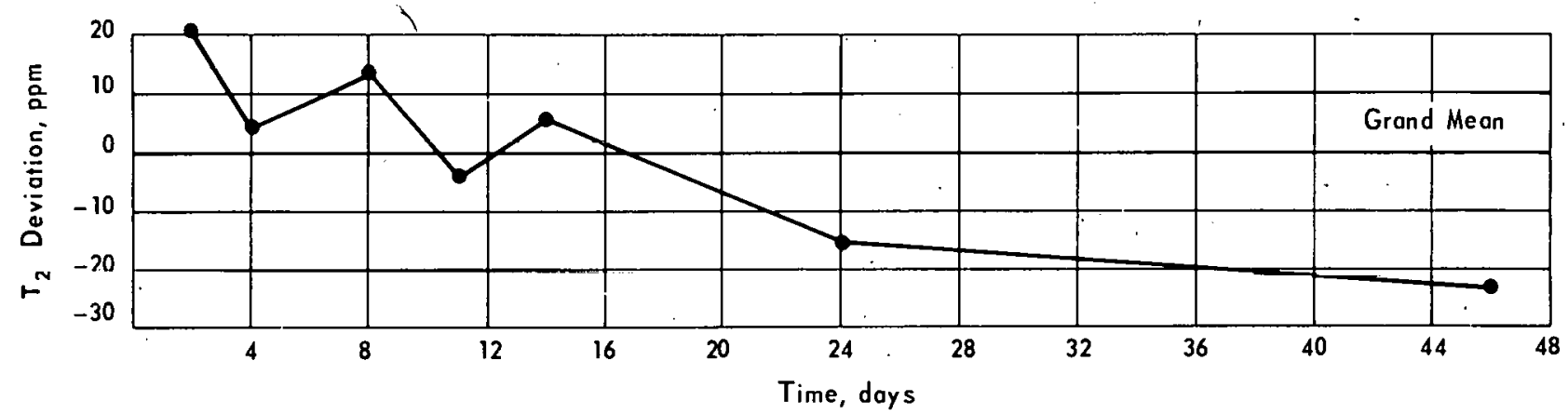

FIGURE 14 - Deviation of tritium daily means from grand mean (1\% DT standard). 


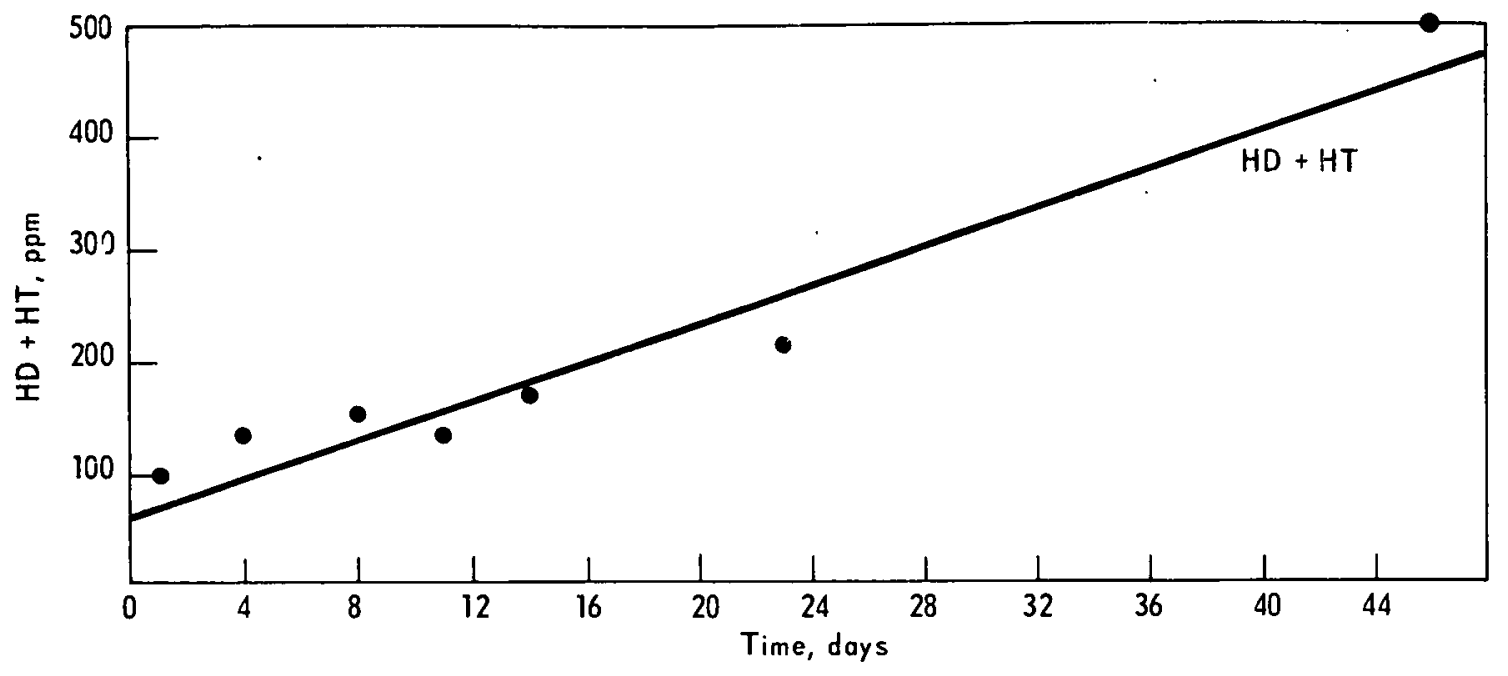

FIGURE 15 - Protium ingrowth in $1 \%$ DT in neon gas standards.

peaks does occur. To a limited extent this overlapping may be corrected by lowering the sample pressure, but this adjustment will also increase the inaccuracy of integration of the DT peak area. Thus, there is a systematic error in the DT values at concentrations less than about $1,000 \mathrm{ppm}$. The integration of the overlapping peak areas occurs as follows (see Figure 16). In the absence of tritium, integration of the DT peak would normally occur from point $A$ to point $C$ on the baseline, but for the overlapping peaks the integration proceeds from the point $A$ to the vertical line $B D$, and the area $C B D$ is not integrated as part of the DT isotopic peak area. The extent of the error in this type of integration is difficult to estimate because the exact form of the peak shapes for both the DT and tritium are variable from sample to sample. However, it is obvious that a small portion of the leading edge of the tritium peak is integrated as part of the trailing edge of the DT peak and, therefore, compensates to some extent the loss of the unintegrated portion of the DT peak.

\section{METHOD ACCURACY}

The determination of method accuracy is difficult at the low concentration levels at which the chromatograph performs, and a comprehensive assessment of accuracy for all the impurity gases has not been achieved. Data were collected for nitrogen and HD determinations by chromatography and mass spectrometry which will serve to illustrate the accuracy by comparison of the results by the two independent methods. The sample analyzed by the two instruments was deuterium with nitrogen and HD impurities known to be present. The deuterium gas had been sampled a large number of times by mass spectrometry, and the comparative results are shown in Table 8. The results for $\mathrm{HD}$ at the relatively high level for chromatography analysis agree to about $2 \%$ with the mass spectrometry value. The difference between the two nitrogen values is about $100 \mathrm{ppm}$ or $20 \%$ relative difference. At $1,000 \mathrm{ppm}$ or less, the accuracy of the mass spectrometer is considered to be no better than $50 \%$, so the agreement between the two techniques is considered acceptable.

For assessing the analytical acmurary at a level of, say, 500 ppm, two general schemes may be considered.

a. A sample containing approximately 500 ppm of impurities may be analyzed by the gas chromatograph and a second instxument with similar accuracy and detection limits.

b. An accurately known standard gas mixture may be analyzed by the chromatograph.

The first scheme presently has its limitations because no other instrument at Mound Laboratory can achieve both the specificity for hydrogen isotopes and the accuracy of the chromatograph at low concentration detection levels. The second scheme has similar deficiencies in that the technology is not available for preparing stable hydrogen isotopic mixtures containing tritium at low concentrations, and no instrument other than the 


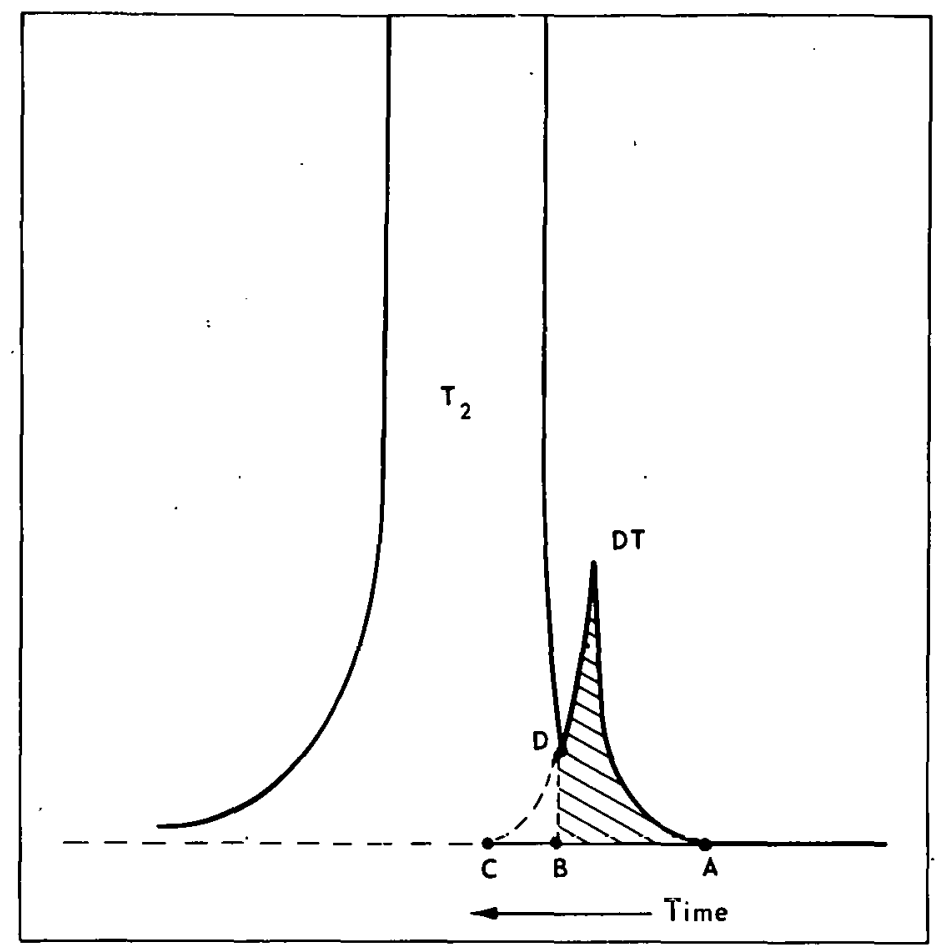

FIGURE 16 - Illustration of DT integrated peak area for overlapping $D T$ and tritium peaks.

Table 8

\begin{abstract}
COMPARISON OF TWO INSTRUMENTAL METHODS FOR DETERMINING NITROGEN AND HD IN DEUTERIUM
\end{abstract}

Mass

Spectrometry

HD

$\mathrm{N}_{2}$

Number of

Measurements
$0.72 \underline{8} \div$

$5 \underline{65} \mathrm{ppm}$

15 triplicates
Gas

Chromatography

0.7158

$47 \underline{4} \mathrm{ppm}$ chromatograph is presently capable of qualifying such a standard. These arguments illustrate the barrier to be overcome before a comprehensive accuracy assessment is possible for the chromatograph ,

\section{E. IIIGII PROBABILITY SYSTEMATIC ERRORS}

HT BUILDUP

The presence of sorbed hydrogen on the internal surfaces of the chromatograph was revealed in the first impurities analyses performed after the instrument was fully operational. An increase in protium level as HT in purified tritium samples was recorded for samples which were stored for periods of $15 \mathrm{~min}$ to $1 \mathrm{hr}$ in sampling lines. This phenomenon was not unexpected since the apparatus had not been conditioned with tritium prior to installation, and the internal surfaces had ample exposure to hydrogen during development activities. Therefore, the HT results for approximately the first two months of operation were systematically higher in concentration because of isotopic exchange of sorbed protium with 
sample tritium. The system became more. "conditioned" as more and more tritium samples were determined, and the protium buildup became less of a problem. In addition to the inner surfaces of the stainless steel sampling manifold, pressure transducer, and column, other very likely sources of protium were surfacebonded water and protium on the alumina column packing, and joints in sampling lines which were silver soldered rather than welded.

For tritium samples from a thermal diffusion product tank where analytical results were used as an indicator of separation performance, the systematic error was accepted without changing the experimental procedure if the sample contained a relatively large amount of true HT. However, for samples in which greater reliability of results was required, the protium buildup was negated by feeding fresh samples from the source to the sampling valves for each replicate rather than storing a quantity of samples in "conditioned" lines for use as needed. After a period of weeks, sample replication indicated that "conditioning" had reduced the quantity of sorbed protium available for isotopic exchange.

\section{ERROR FROM VALVE LEAKAGE}

A source of error in the determination of argon and nitrogen impurities was a small amount of leakage of these boxline atmospheric gases into the sampling valve when the sample loop was evacuated. When analyzed as a "blank" run without actual sample in the loop, the argon leakage resulted in a peak equivalent to about $100 \mathrm{ppm}$ or less if an actual sample had been analyzed. Nitrogen, being present in the boxline at far lower concentrations, has seldom shown as an integratable peak in blank runs. This leakage presents a serious error for argon impurity in a range from 50 to 500 ppm. However, results from blank runs have in practice been subtracted from the results of argon.impurity determinations in order to negate the effects of the leakage.

\section{DT - TRITIUM PEAK OVERLAP}

Error is present in DT determinations from the overlap of DT and tritium peaks. A previous section contains the discussion. (System Reliability Method Performance, Part C):

\section{PRESSURE TRANSCUCERS}

Two pressure transducers have been used in the instrument sampling system. The first had a $0-2700 \mathrm{~mm} \mathrm{Hg}$ range, and the second has an $0-800 \mathrm{~mm} \mathrm{Hg}$ range and is presently in use. The second transducer was placed in the system in order to match the transducer range more closely with actual operating pressures. Both transducers and the readout electronics were calibrated and certified by the Mound Standards Laboratory, and the calibration data for the initial calibration are presented in Table 9 . Both pressure measuring systems were certified to be accurate to $0.2 \%$ of full-scale readings. Although this error is small in comparison with other error sources, there is the potential for error from long-term drift of electronics in addition to the 0.28 error. Daily calibration checks are performed to eliminate this electronic drift so that the $0.2 \%$ error is the only error from pressure readings.

\section{F. ERROR CURVES AT LOW CONCENTRATIONS}

The estimates of errors in the concentration range of 50-2000 ppm are calculated by summing the errors of instrument components. This error calculation is described in section IV-A and is used for the low concentraliun range since stable and/ur accurate isotopic standards are not available in this range for error determination. The calculations produce relative standard deviation values which increase with decreasing concentration, and a representative error curve in this range is presented in Appendix B. 
Table 9

TRANSDUCER CALIBRATION DATA

Transducer No. I

Range: 0-2700 $\mathrm{mm} \mathrm{Hg}$

$\begin{array}{rc}\begin{array}{c}\text { Std }^{\mathrm{a}}(\mathrm{mm}) \\ \hline 300.0\end{array} & \begin{array}{c}\text { Pressure } \\ \text { Readout } \\ (\mathrm{mm})\end{array} \\ 600.0 & 298.2 \\ 900.0 & 597.4 \\ 1200.0 & 897.6 \\ 1500.0 & 1198.6 \\ 1800.0 & 1499.4 \\ 2100.0 & 1800.4 \\ 2400.0 & 2101.0 \\ 2700.0 & 2400.8 \\ & 2699.8\end{array}$

Transducer No. 2

Ránge: $0-800 \mathrm{~mm} \mathrm{Hg}$

\footnotetext{
${ }^{a}$ Reference standard: Ruska DDR
}

\begin{tabular}{cc}
$\begin{array}{c}\text { Std }^{a} \\
(\mathrm{~mm})\end{array}$ & $\begin{array}{c}\text { Pressure } \\
\text { Readout } \\
(\mathrm{mm})\end{array}$ \\
\hline 0.0 & 0.0 \\
102.38 & 102.2 \\
202.63 & 202.6 \\
301.65 & 302.0 \\
401.84 & 401.6 \\
500.56 & 501.4 \\
601.43 & 602.2 \\
706.27 & 706.8 \\
801.00. & 800.8
\end{tabular}

\section{Limitations of Present System}

\section{A. MANUAL OPERATION - SAMPLE THROUGHPUT}

The number of samples that may be analyzed per day is limited mainly by the lengthy sampling procedure that must be performed manually and by the time for separation and detection per sample which is about $30 \mathrm{~min}$. Additionally, there is a $2-\mathrm{hr}$ stabilization time required for the system to equilibrate after the electronics are turned on, and if both chemical and isotopic impurity analyses are required in one day, a changeover time of about $3 \mathrm{hr}$ is required between methods. These restrictions necessitate fairly rigid planning and coordination of aralytical requests.

\section{B. ORTHO-PARA ISOMER SEPARATION}

The ortho and para nuclear spin isomers of hydrogen and deuterium are separated by the alumina column. The isomers may be equilibrated to give one peak by coating the alumina packing with $\mathrm{Fe}_{2} \mathrm{O}_{3}, 2$ but this procedure was not used for the alumina placed in the instrument. The presence of the isomers does not presently affect the quality of analyses being performed, but does inhibit accurate calibration of hydrogen and deuterium and thus prevents their accurate determination. The presence of the spin isomer peaks on chromatograms does complicate their interpretation if very small quanti-. ties, i.e. <100 ppm, of HT and DT are being measured.

\section{LIMITED ANALYTICAL RANGE}

The instrument system was primarlly designed for the concentration range of $100 \mathrm{ppm}$ to about $2000 \mathrm{ppm}$, although it may be used effectively at higher levels. The instrument does not presently possess the capability of determining isotopic species at levels higher than about $4 \%$. In order to operate at these higher analytical ranges (5\% - $95 \%)$, different column parameters would be required to separate the isotopes adequately, and obviously new calibrations throughout this range would be required. 


\section{References}

1. W. R. Moore and H. R. Ward, J. Phys. Chem., 64, 832 (196.0).

2. M. Conti and M. Lesimple, J. Chromatogr., 29, 32-43 (1967).

3. P. Van Urke and L.Lindner, Int. J. Appl. Radiat. Isot., 23, 239 (1972).

4. C. Genty and R. Schott, Anal. Chem.; $\underline{42}, 7 .(1970)$.

5. E. Obermilier and R. Freedman, J. Gas Chromatogr., 3, 242 (1965).

6. R. Bethea and M. Meador, J. Chromatogr. Sci.' I, 655 (1969).

\section{Bibliography}

The following is a list of journal references to the separation of hydrogen isotopes. The list is chronological and is selective; only the most pertinent references are included.

1. W. R. Moore and H:R. Ward, J. Am. Chem. Soc., 80, 2909-10 (1958).

2. H. A. Smith and P. P. Hunt, J. Phys. Chem., 64, 383-84 (1960).

3. W. A. VanHook and P. H. Emmett, J. Phys. Chem., 64, 673-75 (1960).

4: W: R: Moore and H. R. Wärd, J. Phys. Chem., 64, 832 (1960).

5. G. F. Shipman; Anal: Chem: 34, 877-88 (1962).

6: - J. King; J. Phys: Chem.; 67, 1397 (1963).

7. E. H. Carter and H. A. Smịth, J. Phys: Chem.; 67, 1512-16 (1963).

8. M. Venugopàlan änd K. Kutschke, Can. J. Chem., 41, 548 (1963).

9. D. I. West and A. L. Marston, J. Am. Chem. Soc.; 86, 4731 (1964):

10. W. J: Hauback, et al., J. Phys. Chem., 71, 1398-1402 (1967)..

11. M. L. Conti and M. Lesimple, J. Chromatogr., 29, 32-43 (1967).

12. C. Genty and R. Schott, Anäl. Chem., 42 ; 7-11 (1970).

13. 'P. Van Urke and L. Lindner, Int. J. Appl. Radiat. Isot., 23, $239-41$ (1972).

\section{Acknowledgements}

The authors wish to acknowledge, with thanks, the advice and assistance of Dr. William Rutherford in. establishing some of the design parameters for. separating the hydrogen isotopes. 
Appendix A

Complete Flow Schematic and Parts List 


\section{Complete Flow Schematic and Parts List}

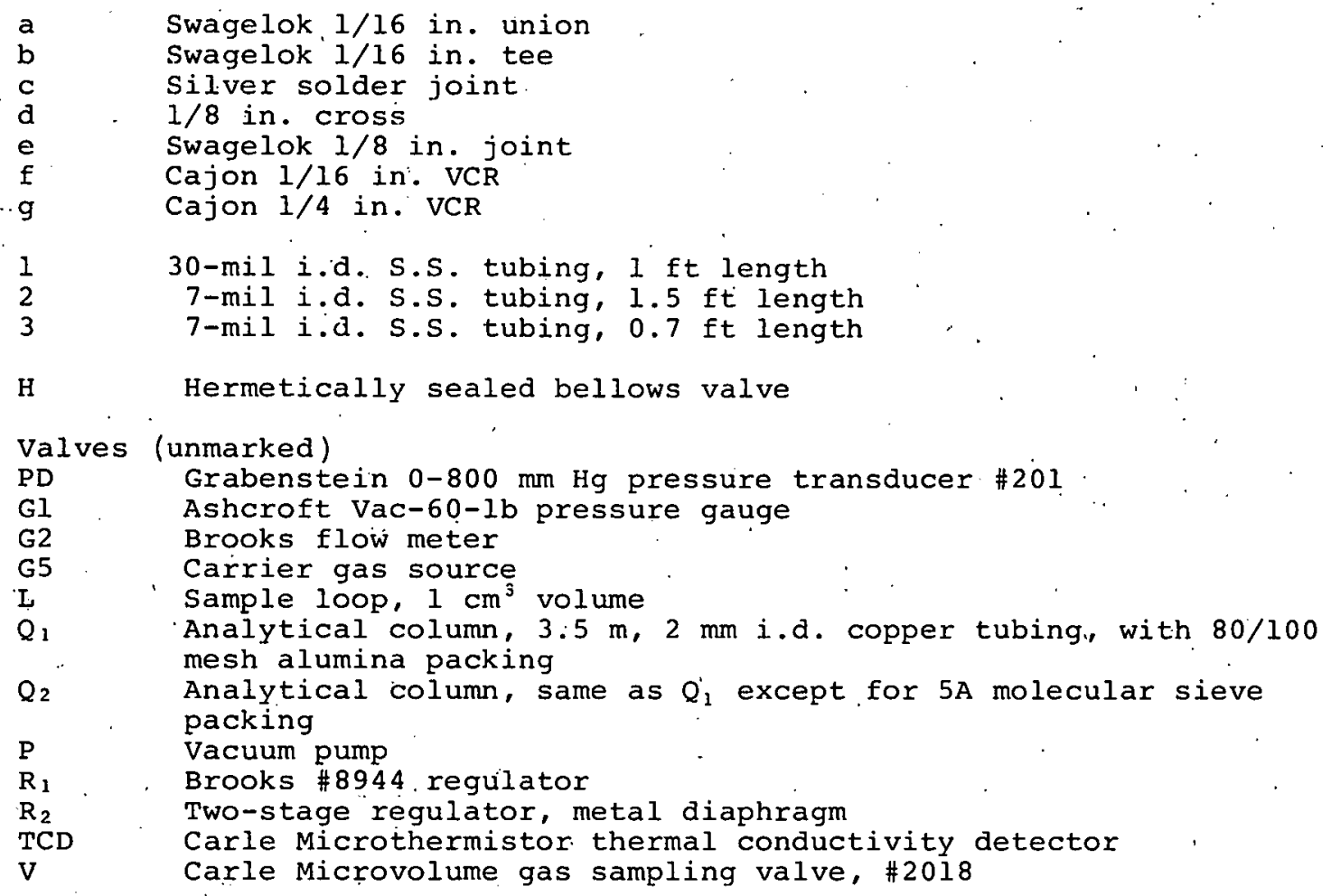

\section{Electronic Parts List}

Detector Recorder Integrator Pressure Readout
Carle \#100 detectcr control unit Hewlett-Packard \#7101R Hewlett-Packard \#3371B. Doric \#DS-300-T?. 


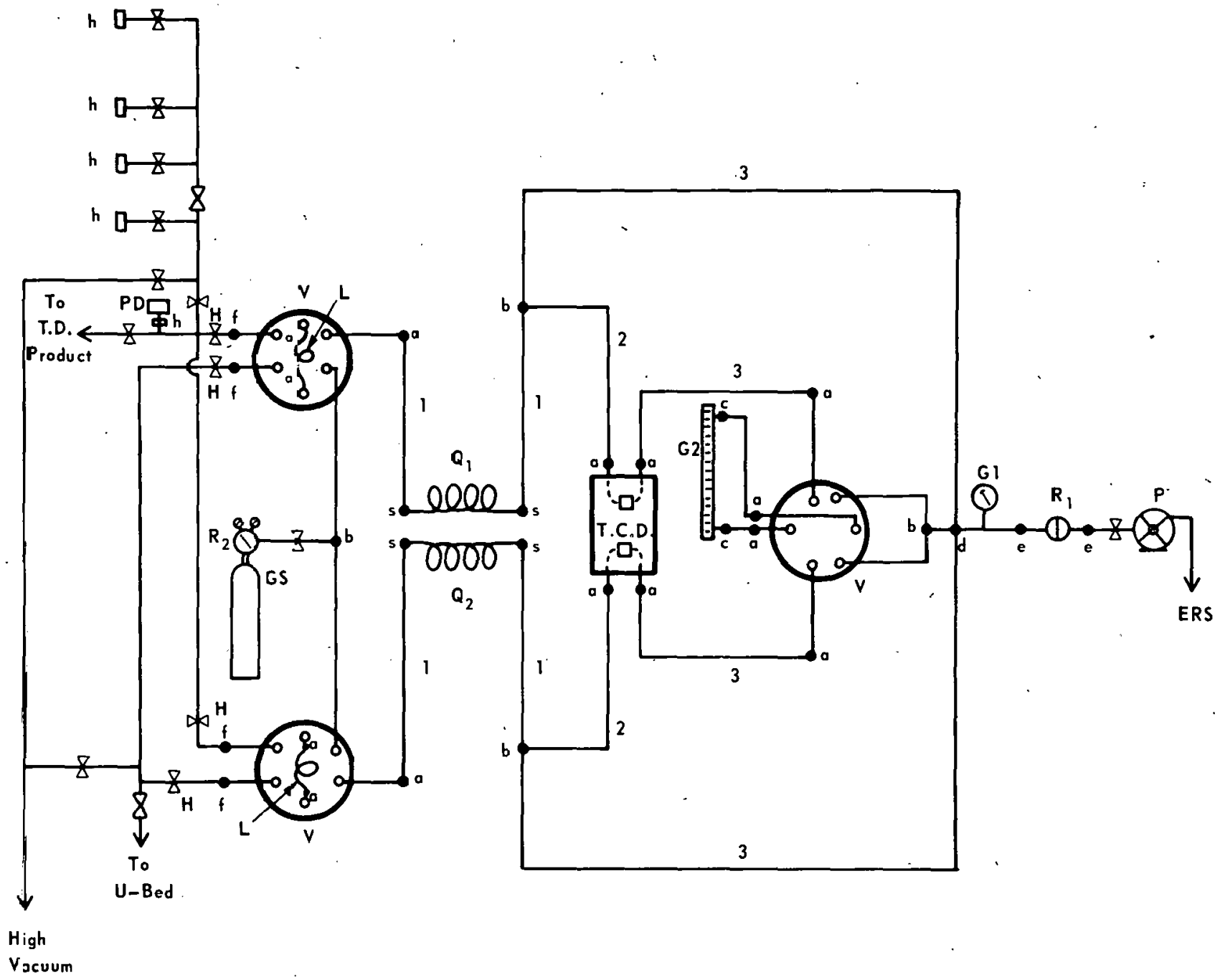

GAS FLOW SCHEMATIC

N 
Appendix B

Error Curve for Impurity Determinations 


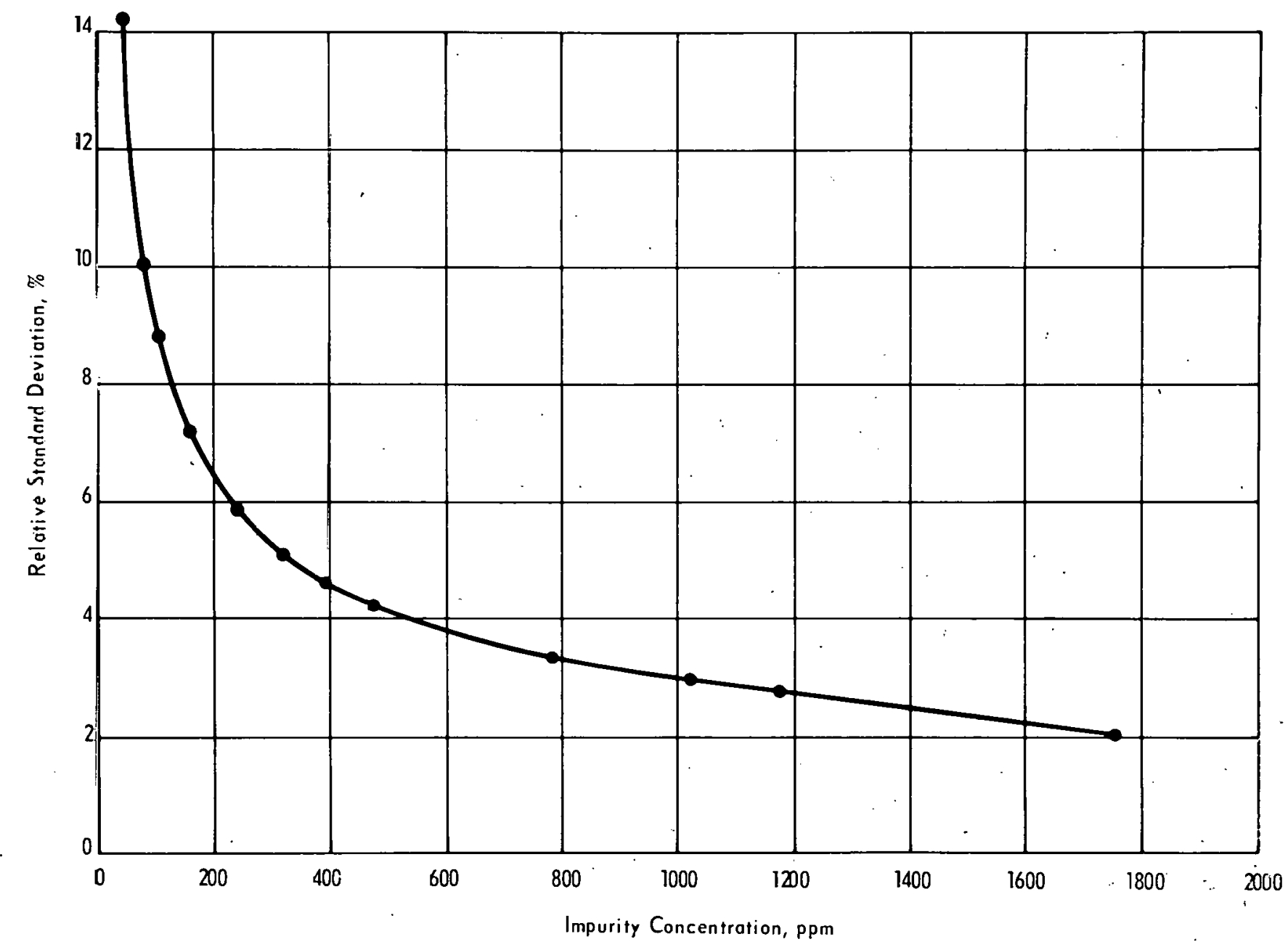

ERROR CURVE FOR CONCENTRATIONS BELOW 2000 PPM FROM PROPAGATION OF ERROR CURVE CALCULATIONS 


\section{Distribution}

EXTERNAL

TID-4500, UC-4 (159)

Consultants

C. F. Curtiss

University of Wisconsin

C. F. Eck

Miamisburg, Ohio

D. F. Griffing

Miami University

J. H. Leonard

University of Kentucky

R. E. Miers

Ft. Wayne, Indiana

W. E: Moddeman

University of Dayton Research Institute

G. W. Powell

Ohio State University

A. Shapiro

University of Cincinnati

II. F. Swift

University of Dayton Research Institute

D. White

University of Pennyslvania

H. W. Mattson, Monsanto Company

R. K. Flitcraft, MRC

INTERNAL
D. R. Bohl
W. T. Cave
C. W. Huntington
L. V. Jone's
C. Ki,nard
J. R. McClain

T. B. Rhinehammer

D. E. Sellers

R: F. Valldo

$\mathrm{D}$. K. Warner

Publications

Library (15) 